\title{
WestVirginiaUniversity
}

THE RESEARCH REPOSITORY @ WVU

Graduate Theses, Dissertations, and Problem Reports

2017

\section{The Effects of Signaled Reinforcer Duration on Preference}

Anthony C. Oliver

Follow this and additional works at: https://researchrepository.wvu.edu/etd

\section{Recommended Citation}

Oliver, Anthony C., "The Effects of Signaled Reinforcer Duration on Preference" (2017). Graduate Theses, Dissertations, and Problem Reports. 6347.

https://researchrepository.wvu.edu/etd/6347

This Thesis is protected by copyright and/or related rights. It has been brought to you by the The Research Repository @ WVU with permission from the rights-holder(s). You are free to use this Thesis in any way that is permitted by the copyright and related rights legislation that applies to your use. For other uses you must obtain permission from the rights-holder(s) directly, unless additional rights are indicated by a Creative Commons license in the record and/ or on the work itself. This Thesis has been accepted for inclusion in WVU Graduate Theses, Dissertations, and Problem Reports collection by an authorized administrator of The Research Repository @ WVU. For more information, please contact researchrepository@mail.wvu.edu. 
The Effects of Signaled Reinforcer Duration on Preference

\author{
Anthony C. Oliver \\ Thesis Submitted to the Eberly College of Arts and Sciences at West Virginia University in \\ partial fulfillment of the requirements for the degree of \\ Master of Science \\ in \\ Psychology
}

Kennon A. Lattal, Ph.D., Chair

Michael Perone, Ph.D.

Nicholas A. Turiano, Ph.D.

Department of Psychology

Morgantown, West Virginia

2017

Keywords: preference; concurrent chain; reinforcer duration; choice; signals

Copyright 2017 Anthony Oliver 


\section{ABSTRACT \\ The Effects of Signaled Reinforcer Duration on Preference}

\section{Anthony C. Oliver}

It has been suggested that reinforcers of different durations can be made more discriminable by pairing specific stimulus conditions with different durations (Bonem \& Crossman, 1988). The purpose of the current experiment was to assess the effects of signaling reinforcer duration prior to reinforcer onset on initial-link responding under a concurrent-chains schedule of reinforcement. Initial-link responding was assessed across two sets of reinforcer durations (2- vs. 6-s hopper access and 6- vs. 10-s hopper access) and conditions in which terminal-link stimuli were the same (e.g., both red) and different (e.g., white, blue, or yellow). Preference was defined as the key with the proportion of responses greater than 0.5 . Preference for the longer-duration reinforcer occurred for three of four pigeons when presented as a choice between $2 \mathrm{~s}$ and $6 \mathrm{~s}$. One of four pigeons preferred the longer duration reinforcer when presented with $6 \mathrm{~s}$ vs. $10 \mathrm{~s}$. The inclusion of differential terminal-link stimuli did not enhance preference for the longer duration relative to conditions in which the terminal-link stimuli were undifferentiated across both sets of reinforcer durations. 


\section{Acknowledgements}

Thank you to Andy Lattal for guiding me through this processes. I appreciate your patience and feedback throughout the completion of this project. Thank you to my committee members, Mike Perone and Nick Turiano, for their insightful feedback regarding this project. Thank you to my friends and family for providing support over the last several years. Without you, none of this would have been possible. Finally, a special thank you to Leigh Pratt, who provided unconditional support throughout this process. Thank you so much for being the amazing person you are. 


\section{Table of Contents}

\section{Contents}

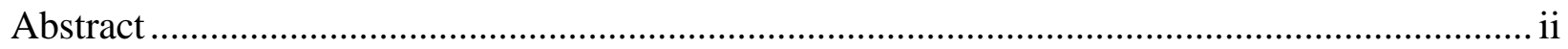

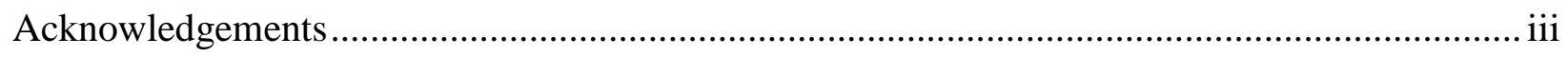

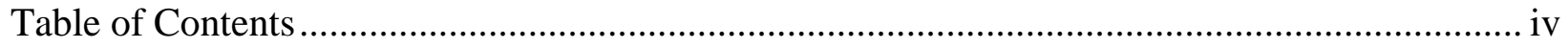

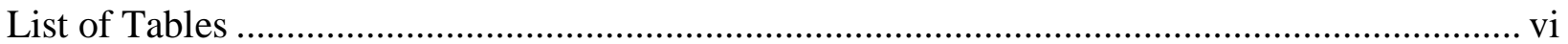

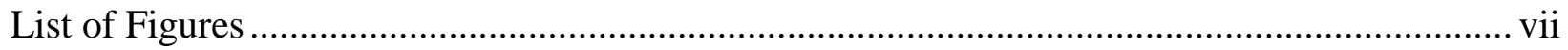

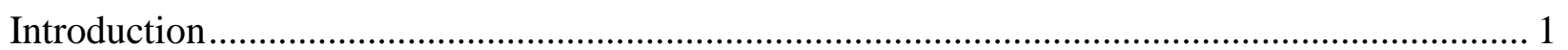

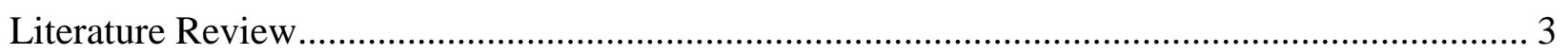

Effects of Reinforcer Duration ................................................................................. 3

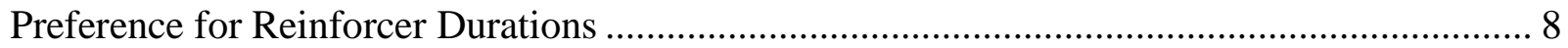

Stimuli Correlated with Reinforcer Duration .................................................................. 10

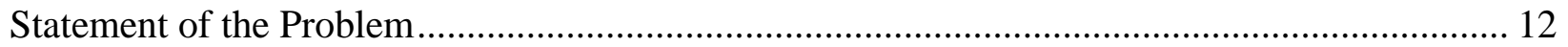

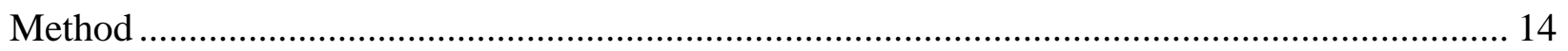

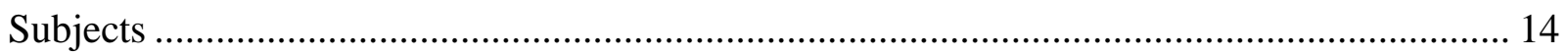

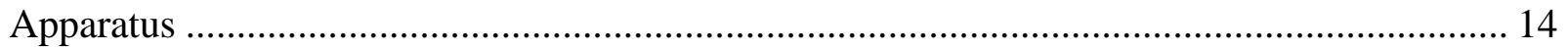

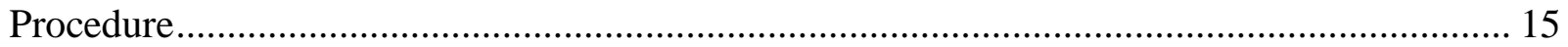

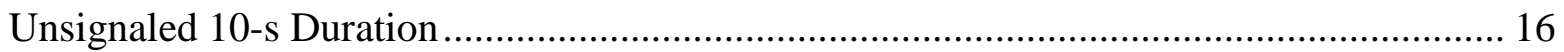

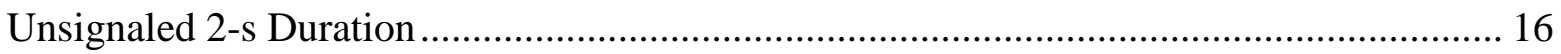

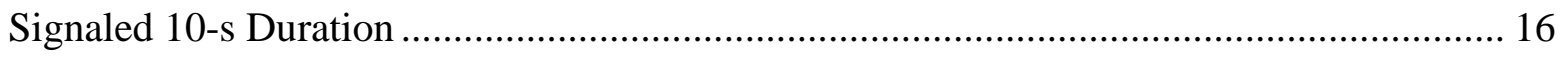

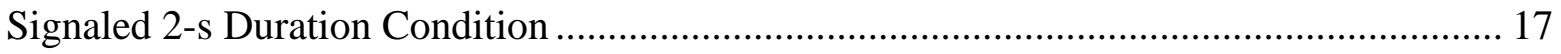

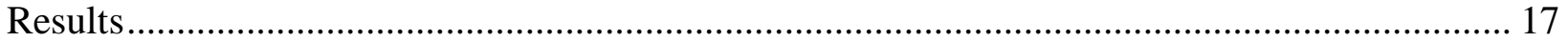

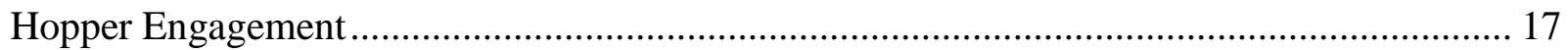

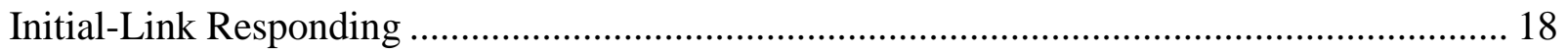

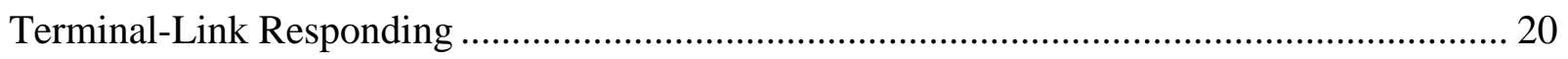

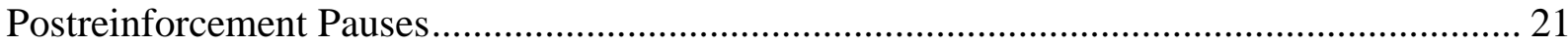

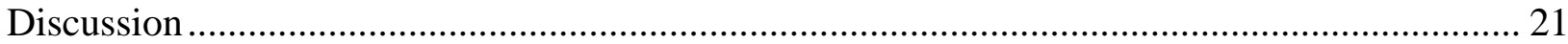

The Effects of Differential Terminal-Link Stimuli on Preference ..................................... 22

Effects of Reinforcer Duration on Preference ................................................................. 25

Postreinforcement Pauses and Terminal-Link Responding ........................................... 26

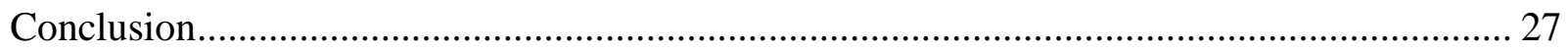

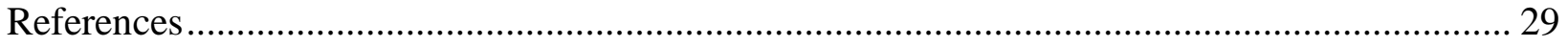




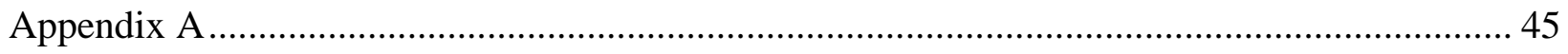




\section{List of Tables}

Table 1. The sequence of conditions, number of sessions, and reinforcer durations for each

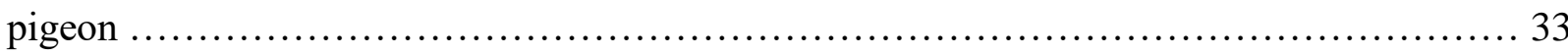




\section{List of Figures}

Figure 1. A diagram of the concurrent chains procedure used in the experiment....

Figure 2. Average engagement with the food hopper per presentation over the last six sessions of each condition.

Figure 3. Distribution of eating times at each programmed hopper presentation for all four pigeons. 36

Figure 4. Mean choice proportions for the longer duration reinforcer across conditions for all pigeons.

Figure 5. Absolute initial-link response rates for the last six sessions of each condition for all pigeons.

Figure 6. Absolute initial-link response rates for the first six and last six sessions of each condition for all pigeons.

Figure 7. Area under the curve analysis of preference for the last six sessions of each condition for all pigeons.

Figure 8. Relative response rates of both the left and right response keys during the initial links for the last six sessions of each condition for all pigeons.

Figure 9. Terminal-link response rates for the last six sessions of each condition for all pigeons. ...

Figure 10. Mean postreinforcement pauses during the last six sessions of each condition for all pigeons.... 


\section{Introduction}

The effect of a reinforcer is a function of several of its parameters, one being its magnitude, which is the "amount" of a reinforcer that is delivered following a response. On closer inspection, reinforcer magnitude is not as well understood as other reinforcer parameters such as delay and frequency. A common method for assessing the effects of reinforcer magnitude is to manipulate the duration of reinforcer access (Bonem \& Crossman, 1988). This approach, in particular, has yielded mixed results. In some cases, no systematic effects of hopper access duration have been reported (e.g., Catania, 1963), but in others there has been a positive relation between reinforcer duration and response rate (e.g., Catania, 1963), behavioral allocation (Brownstein, 1971), or choice for the longer-duration reinforcer (e.g., Neuringer, 1967). These inconsistent findings may be related to a number of factors, including the relative differences in the reinforcer magnitudes examined (Lendenmann, Myers, \& Fantino, 1982; Neuringer, 1967), the type of reinforcement schedule used (Catania, 1963), or even the food hopper type used to deliver the reinforcer (Epstein, 1985).

Presenting a reinforcer entails two things: its duration and its onset. When food-access duration is used to study reinforcer magnitude, the reinforcer onset remains constant across all durations and the temporal duration changes across parametric manipulations. Thus, there is no distinction between a long and a short reinforcer duration at the onset of reinforcement. Rather, responding must come under the control of the subsequent temporal aspect of the reinforcer presentation - its duration. When, for example, a food hopper is presented for $2 \mathrm{~s}$ versus $6 \mathrm{~s}$, the 6-s reinforcer only becomes discriminable at some point after $2 \mathrm{~s}$ have lapsed. By contrast, in another type of reinforcer magnitude manipulation, when a $95 \%$ concentration of sucrose water is compared to a $5 \%$ concentration the difference between the two reinforcers is discriminable 
immediately at reinforcer onset. Where unsystematic effects of reinforcer duration on responding have been reported, such effects may be related to both the way in which duration is studied (e.g., hopper duration versus sweetness concentration) and the relative contributions of reinforcer onset and subsequent reinforcer duration to response maintenance.

The contribution of reinforcer onset could be assessed by comparing the behavioral effects of different reinforcer durations when reinforcer onsets are associated with either the same or different stimuli. One way of doing this is by illuminating a feeder a same or different stimulus as a function of reinforcer duration. A potential confound, of such a procedure is the possibility that adding a second stimulus to an already well-established configuration of stimuli (i.e., the reinforcer) could result in the former being overshadowed by the latter stimuli (c.f. Mackintosh, 1976; Pavlov, 1960). Another approach would be to use stimuli that precede reinforcer onset. One way to do this is with a concurrent-chains schedule, which is a commonly used procedure to analyze preference.

The present experiment was a further analysis of reinforcement duration effects on the operant choice responding of pigeons in concurrent-chained schedules as a function of signaling upcoming reinforcer durations in the terminal links of the schedule. The three topics most germane to this proposal - the behavioral effects of reinforcer duration, preference for different reinforcer durations, and the effects of signaling reinforcement availability - are reviewed in the next section. This is followed by a proposal for an experiment employing concurrent chains schedules to examine how signaling upcoming reinforcer durations affects preference. 


\section{Literature Review}

\section{Effects of Reinforcer Duration}

Reinforcer magnitude is commonly manipulated by changing the amount of time food is available to the pigeon parametrically across several conditions (Bonem \& Crossman, 1988). Jenkins and Clayton (1949) examined the effects of 2-s and 5-s reinforcer durations on responding maintained by a variable-interval (VI) 1-min schedule. The number of responses during a session was a function of the duration of access to the reinforcer, with somewhat more responses occurring when the reinforcer duration was longer. Mean response rate for the five pigeons in the 2-s condition was 42 responses per minute, which, increased to 51 responses per minute in the 5-s duration condition. There appeared to be a sequence effect in that relatively larger increases in responding were observed when the pigeons were exposed to the 2-s reinforcer duration prior to the 5-s duration. Although differences in response rates were observed, only mean response rate for each subject were reported and there was considerable variability in response rates across pigeons. Additionally, the evidence for reinforcer duration effects on response rate relied in part on cumulative records, which also did not reveal clear differences between the two durations.

In other experiments, changes in reinforcer magnitude have been reported to yield only transient changes in behavior. Keesey and Kling (1961) examined the effects of changes in reinforcer magnitude on key pecking in two experiments. Experiment 1 assessed the effects of reinforcer magnitude using stimulus-probe technique and Experiment 2 examined the effects of reinforcer magnitude at different times within experimental sessions. During Experiment 1, key pecking was reinforced according to a multiple VI 4-min schedule. In one component, baseline, the key was transilluminated purple and responses were reinforced with 1 seed. In the second 
component, the experimental amount condition, the key was transilluminated a specific color depending upon the programmed reinforcer magnitude. In the experimental amount conditions, reinforcer magnitude, defined as the number of grain pieces delivered, varied across separate daily sessions in which a different stimulus was associated with either of the four magnitudes (i.e., 4 one-quarter peas were delivered when the key light was orange, 4 one-half peas when the light was blue, 2 halves and 2 wholes when it was green, and 4 whole peas when it was red). When responding was stable in the presence of each discriminative stimulus, the VI 4-min baseline condition (with 1 grain of corn as the reinforcer) was reinstated. On this latter baseline, extinction probes (i.e., each of the discriminative stimuli were presented for $90 \mathrm{~s}$ ) were introduced. The probe tests had no systematic effect on response rates in the different components, indicating that stimuli correlated with reinforcer magnitude may not be sufficient for producing changes in behavior in single schedules.

In Keesey and Kling's (1961) second experiment, the effects of differing reinforcer amounts on key pecking maintained by a VI 4-min schedule of reinforcement were assessed during the first minute of the session and for the full session. The largest reinforcer magnitude ( 8 seeds) resulted in the highest response rate during the first minute of the session. When response rates for the entire session were compared, however, there was no difference between the different reinforcer magnitudes. Thus, the effects of reinforcer magnitude were transient, dissipating with increasing exposure to the same magnitude across a session. Keesey and Kling suggested the lack of consistent effects of reinforcer magnitude may have been due to the use of a single schedule of reinforcement, stimulus generalization between the different discriminative stimuli, and response induction between responding maintained by the different magnitudes. 
Catania (1963) assessed, across successive conditions, the effects of reinforcer durations of 3.0, 4.5, and $6.0 \mathrm{~s}$, on responding maintained by a single VI 2-min schedule. Response rates were similar for the 3.0-s and 4.5-s reinforcer durations and response rates decreased slightly with two of the three pigeons at the 6.0-s duration. Thus, no systematic effects of reinforcer duration were observed. There was indirect evidence that the amount consumed differed as a function of at least the 6.0-s magnitude because the pigeons reportedly gained more weight when this duration was in effect. Catania's results are similar to those of Keesey and Kling (1961) in that he failed to find a systematic relation between reinforcer duration and response rates when single schedules of reinforcement maintained responding.

Other experiments in which single schedules of reinforcement also have yielded mixed findings with respect to reinforcer duration effects on response rates. When reinforcer duration was increased from 1 to 9 s, Staddon (1970) found corresponding decreases in overall response rate and increases in pausing following reinforcer delivery on fixed-interval (FI) schedules. Powell (1969), however, found that postreinforcement pauses (PRPs) were consistently shorter when reinforcer duration was $4 \mathrm{~s}$ relative to when it was $2.5 \mathrm{~s}$ when responding was maintained by a fixed-ratio (FR) schedule. Thus, in single FI and FR schedules, the effects of changes in reinforcer duration on the same dependent measure are contradictory.

To summarize, when reinforcer duration is assessed parametrically using single schedules of reinforcement, the findings have been mixed. When different durations are presented across conditions, duration within a condition is fixed so that there is no contrasting exposure to the other durations in the experiment. Furthermore, each of the different durations have been associated with the same stimuli at the onset and throughout the reinforcer cycle (but cf. Keesey \& Kling, 1961). 
An alternative method for studying the effects of reinforcer duration is to make different durations available concurrently, because, as Catania (1963) proposed, this might yield greater sensitivity of response rates to reinforcer magnitude. Following the parametric, comparison of three reinforcement durations described above, Catania arranged for the same pigeons a concurrent VI 2-min VI 2-min schedule in which different reinforcer durations were programmed in either component. In these concurrent arrangements, response rates were an orderly function of reinforcer duration. Brownstein (1971) reported a similar (matching) relation between reinforcer duration and time allocation on concurrent variable-time (VT) schedules of reinforcement. Fantino, Squires, Delbrück, and Peterson (1972), however, assessed the effects of reinforcer duration on response allocation in several concurrent VI VI schedules with different mean interfood intervals and did not find strict matching. Rather, undermatching occurred for six of the six pigeons, indicating a bias for the shorter duration reinforcer relative to the larger duration. Furthermore, for only three of the six pigeons was there a systematic relation between reinforcer duration and choice proportion. The effects of reinforcer duration on responding in concurrent schedules have proven to be similarly inconclusive to those of single schedules of reinforcement.

In addition to the way in which different reinforcer durations are scheduled, the study of this reinforcement parameter presents several methodological challenges. One is the type of feeder used during these experiments and the other is engagement with the reinforcer. In early experiments, not much attention was paid to the type of feeder used to arrange the different reinforcer durations. This may have been a source of variability in the effects reported because feeder design can influence the amount of a reinforcer that is available. Epstein (1985) found systematic differences in food consumed as a function of the type of hopper. With some feeders, 
the maximum amount of reinforcement delivered in a single reinforcer cycle duration was $7 \mathrm{~s}$ regardless of the programmed duration. This is an issue because the reinforcer durations in different experiments have ranged range from as brief as $2 \mathrm{~s}$ (Lendenmann et al., 1982) to as long as $10 \mathrm{~s}$ (Neuringer, 1967). Using a concurrent-chains procedure with different reinforcer durations occurring following responding in the terminal links, Neuringer (1967) found preference for a 6-s over a 2-s reinforcer but there was indifference between a 6-s vs. a 10 -s reinforcer. Based on Epstein's (1985) results, it could be that indifference at relatively long hopper presentations occurred because similar amounts of food were functionally available at the different durations. Neuringer reported only that food hopper was used to dispense mixed grain to the pigeons, but he did not indicate the type of feeder. Given this, it well could have been a type that Epstein found untenable.

The second challenge is the discriminability of different reinforcer durations. Catania (1963) found differences in response rates maintained by reinforcer durations of 3, 4.5, and $6 \mathrm{~s}$ when they were studied using a concurrent schedule. Lendenmann et al. (1982) found systematic changes in response rates in the initial links of chained VI VI and chained FI FI schedules when 2, 5, and 8-s duration reinforcers occurred in different conditions at the end of the terminal links. Neuringer (1967) found that changing from a 2 to 4 s reinforcer duration resulted in greater increases in preference for the variable reinforcer key than did such increases when the hopper duration was increased from 6 to $10 \mathrm{~s}$, suggesting that responding may be less sensitive to change when reinforcer durations are relatively long. This observation is consistent with Stubbs's (1968) finding that temporal discriminations by pigeons can be described by Weber's law, that is, with longer stimulus presentations, a larger proportional difference is necessary to control differential choice responding. This in turn suggests that changes involving shorter 
durations (i.e., less than $6 \mathrm{~s}$ ) may have a greater effect on responding than changes between longer durations (i.e., greater than $6 \mathrm{~s}$ ) when the durations are concurrently available (Neuringer, 1967; but cf. Catania, 1963).

In the previous sections choice and preference were used to describe the effects of reinforcer duration on concurrent schedules of reinforcement. Choice generally refers to the allocation of behavior across concurrently available operanda, whereas preference refers to the tendency to select one alternative more frequently than the others, typically from a neutral starting point, as in a concurrent-chains schedule (Baum \& Rachlin, 1969; Mazur \& Fantino, 2014; Rachlin \& Green, 1972). The following section will examine the effects of reinforcer duration on preference in a concurrent-chains arrangement.

\section{Preference for Reinforcer Durations}

The concurrent-chains schedule (Autor, 1960), diagrammed in Figure 1, is widely used to assess preference. Initially, two concurrently available operanda (response keys if the subjects are pigeons) are associated with identical schedules of reinforcement. Responses on either key occasionally produce a stimulus correlated with the terminal link. When either of the terminallink stimuli is produced, the other response key is deactivated and responses in the remaining terminal link are reinforced according to some schedule. After reinforcement, both initial links are reinstated and the process repeats. The measure of choice in this arrangement is relative or, sometimes, absolute response rate in the initial link. Concurrent-chains schedules have been used to assess preference for single versus multiple reinforcers (Moore, 1979), differing probabilities of reinforcement (Spetch \& Dunn, 1987), and different schedules of reinforcement (Duncan \& Fantino, 1970). The advantage of the concurrent-chains schedule over a conventional concurrent schedule as a means of assessing preference is that preference is not confounded by the rates of 
responding generated by different reinforcement schedules or by different rates of reinforcement associated with the different schedules (choices) on each key (Fantino, 1977; Williams, 1994). Rather, relative responding is compared under identical initial-link VI schedules associated with different terminal-link conditions, thereby assuring equal exposure to both terminal links.

The concurrent-chains schedule has been used to assess preference between different reinforcer magnitudes. Ito and Asaki (1982) reported that when the delay to reinforcement was held constant, larger-magnitude reinforcers were preferred over the smaller-magnitude reinforcers. Rats responded on concurrent chained VI FI chained VI FI schedules in which either 1 or 3 pellets occurred at the end of the terminal (FI) links. Although the parameter of interest was the delay to reinforcement, in Experiment 1 preference between reinforcer magnitudes were systematically assessed when the delay to reinforcement was held constant. Choice proportions for all 14 rats were larger for the larger-magnitude reinforcer relative to the smaller reinforcer. Preference for the larger reinforcer increased as a function of increasing delay values.

Initial-link responding is also sensitive to differences in reinforcer duration. Neuringer (1967) assessed pigeons' preferences for reinforcers of different durations and the subsequent effects of these same durations on terminal-link response rates. In the initial link, a single response (i.e., an FR 1 schedule) initiated an FI 5-s schedule in the selected terminal link. In the terminal link two independently timed and concurrently available VI 60-s schedules arranged the delivery of either a reinforcer or a 1-s blackout that would be delivered once the FI schedule had elapsed. One initial link led to a constant 2-s duration reinforcer whereas the other led to a reinforcer that varied in duration ( $2 \mathrm{~s}$ to $10 \mathrm{~s})$ across conditions. Choices in the initial link were functionally related to reinforcer duration, with choice responses favoring the initial link that led to longer reinforcer durations. 
Similar to both Neuringer (1967) and Ito and Asaki (1982), Snyderman (1983) reported that longer-duration reinforcers were preferred relative to shorter duration reinforcers in a concurrent-chains schedule. In this experiment, pigeons responded on concurrent chained VI FT chained VI FT schedules in which either a 2- or 6-s reinforcer was presented after a fixed period of time. Delays in the terminal link were arranged according to four delay ratios, ranging from 6:1 to 1:1 and each initial-link entry was associated with a specific houselight color (i.e., green for left key, red for red key). Although relative response rates for the longer-duration reinforcer, deceased as a function of increasing delays in the 6:1, 3:1, and 3:2 delay ratio conditions, this was not the case for the 1:1 condition. In this condition, irrespective of the delay, relative response rates remained above .5 for the longer duration reinforcer. The effect of the differential terminal-link stimuli cannot be interpreted in this experiment as was never directly compared to a condition in which there were nondifferential terminal-link stimuli, however, this experiment does indicate that reinforcer duration affects initial-link responding.

\section{Stimuli Correlated with Reinforcer Duration}

The use of stimuli associated with reinforcer duration has been suggested as a possible method in enhancing the discriminability of reinforcers of different durations (Bonem \& Crossman, 1988). In a concurrent-chains schedule, this can be done by correlating terminal link stimuli with upcoming reinforcer durations. With other parameters of reinforcement, such as probability or delay, terminal-link stimuli correlated with different outcomes differentially affect preference (Green \& Rachlin, 1977; Snyderman, 1983; Spetch, Belke, Barnet, Dunn, \& Pierce, 1990). Thus, by extrapolating from these experiments, it is possible that including a terminal- 
link stimulus differentially associated with different reinforcer durations may enhance differential preference for a longer reinforcer relative to its unsignaled counterpart.

Using a concurrent chained VI VI chained VI VI schedule, Ploog (2001) found that pigeons generally preferred longer-duration reinforcers when differential initial-link stimuli were correlated with nondifferential terminal-link stimuli with respect to reinforcer duration. Ploog suggested that reinforcer duration and not conditioned reinforcers presented in the terminal links of the concurrent-chain schedules used in the experiment were controlling response allocation in the initial links. Most germane to the present experiment, however, in Condition 1, when the terminal-link stimuli were non-differential and the reinforcer durations were either $3 \mathrm{~s}$ or $6 \mathrm{~s}$, there was no preference for the longer-duration reinforcer; initial-link responding was indifferent. When differential terminal-link stimuli were included, preference for the longerduration $(6 \mathrm{~s})$ reinforcer was greater than when only the initial links were differentially correlated with distinct stimuli.

Ploog's findings are limited, however, because of a number of procedural complications. First, the comparisons were made across rather than within individual subjects, thus there are no within-subject comparisons of differential vs. non-differential terminal-link stimuli. Second, the concurrent-chains procedure used by Ploog was atypical; instead of the conventional arrangement in which the initial-link stimuli are the same (e.g., two green keys), each initial link with signaled by a distinct stimulus (i.e., green and red). As a result, there is no comparison between preferences for larger reinforcers when the terminal links were differential with respect to reinforcer duration, with the initial-link stimuli the same. It is possible that signaling upcoming reinforcer durations at the onset of reinforcement might better control subsequent responding than conditions in which the stimuli are the same 
Green and Rachlin (1977) examined the effects of stimuli correlated with reinforcer probability, also in a concurrent-chains procedure. In the right terminal link a differential stimulus was correlated with the probability of reinforcement (i.e., a green key light when a blackout was programed and a red key light when food was programmed to occur at the completion of the terminal-link schedule requirement). In the left terminal link a yellow key light was presented with either of the reinforcement probabilities in effect. Pigeons preferred the initial link correlated with differential terminal-link stimuli. Snyderman (1983) also included differential terminal-link stimuli, however he failed to include a condition in which the terminallink stimuli were the same. Given Ploog's (2001), Green and Rachlin's (1977) and Snyderman's (1984) results above, coupled with what is known about differentially signaling reinforcer magnitude in multiple schedules, differentially signaling forthcoming reinforcer durations might enhance the differential behavioral effects of different reinforcer durations.

\section{Statement of the Problem}

Although magnitude is a frequently discussed parameter of reinforcement, its behavioral effects not as well understood as parameters such as delay and frequency. Duration of reinforcer access was described by Bonem and Crossman (1988) as one of the most common manipulations of reinforcer magnitude. When duration defines reinforcer magnitude, the source of discriminative control occurs at some time after reinforcer onset. This is because when reinforcers of different durations are presented, they are accompanied by the same stimuli (in the case of pigeons, identical hopper sounds and illumination). It is not until the organism contacts the longer duration of one of the reinforcers that there is a basis for distinguishing them. Additionally, there is little direct evidence that different durations necessarily control differential eating. Only Catania (1963) reported that pigeons' weights increased when exposed to longer 
reinforcer durations. Thus, variables such as the lack of discriminative stimulus control and engagement with the reinforcer might contribute to the rather unsystematic effects of reinforcer duration on responding described in the preceding literature review.

When simple schedules of reinforcement are used to assess the effects of reinforcer duration, the findings are mixed. Some have reported increases in response rates as a function of reinforcer duration (e.g., Jenkins \& Clayton, 1949), whereas others have not (e.g., Catania, 1963). Bonem and Crossman (1988) suggested that stimuli differentially associated with reinforcer duration may control differential responding more effectively. This has been done by presenting reinforcers of different durations in different components of a multiple schedule. Shettleworth and Nevin (1965) reported such differential control of response rates using this arrangement. Differential control of responding by reinforcer duration has also been found using concurrent schedules (Brownstein, 1971; Catania, 1963), but even with these schedules, the effects have been mixed. Catania (1963) reported matching between response rates and reinforcer duration in a concurrent schedule, whereas Fantino et al. (1972) reported undermatching to the longer duration. Even when differential control of responding by reinforcer duration has been obtained in multiple and concurrent schedules, the effects of exteroceptive stimuli and the reinforcer duration itself are confounded.

Another method for investigating signaled reinforcer duration is with concurrent-chain schedules in which the stimulus presented in the terminal link is correlated with a specific reinforcer duration. There is evidence with other reinforcement parameters, specifically, reinforcement probability, that correlating a unique stimulus with each probability is preferred over a condition in which the stimuli are uncorrelated (Green \& Rachlin, 1977). Extrapolating from reinforcement probability to reinforcer duration, including a stimulus that reliably precedes 
reinforcer onset may enhance the preference between two different reinforcer durations in a concurrent-chains schedule. Ploog's (2001) results suggest such an effect, but are not conclusive because both initial- and terminal-link stimuli were correlated with different reinforcement durations. As a result, it could be either of the links or the combination that controlled preferences for the longer-duration reinforcers.

As reinforcers of different duration are not discriminable until some point after their onset, the purpose of the present experiment was to assess the effects of signaling reinforcer duration. This was done using a concurrent-chains procedure in which the terminal-link stimuli that preceded either reinforcer duration were the same (e.g. both red) or different (e.g., blue and yellow). This comparison allowed for an analysis of preference in which reinforcer duration was signaled prior to its onset versus conditions in which was not. Additionally, hopper engagement data was collected in each condition to evaluate its relation with reinforcer preference.

\section{Method}

\section{Subjects}

Four White Carneau pigeons served as subjects. Each was housed separately in a vivarium with a 12:12-hr light/dark cycle and with continuous access to water and health grit in their home cages. Each was maintained at approximately $80 \%$ of its ad libitum body weight (+/$15 \mathrm{~g}$ ) by use of postsession feedings. Each pigeon had a history of responding under a variety of reinforcement schedules.

\section{Apparatus}

An operant chamber with a work area of $31.75 \mathrm{~cm} \mathrm{X} 30.48 \mathrm{~cm} \mathrm{X} 37.47 \mathrm{~cm}$ was used. The work panel contained two 2-cm diameter Gebrands Co. response keys located $9 \mathrm{~cm}$ from the ceiling and $6 \mathrm{~cm}$ for the walls of the chamber. The response keys were transilluminated by $7-\mathrm{W}$, 
28-VDC bulbs. The food hopper was located behind a 5-cm square aperture, $7-\mathrm{cm}$ below the midpoint of the right and left keys and 3-cm above the floor of the chamber. Reinforcers were Purina Nutri-Blend ${ }^{\mathrm{TM}}$ pellets delivered by a Ralph Gerbrands Co, model G5610, food hopper that was illuminated by a 7-W, 28-VDC bulb. During food deliveries a Med Associates model ENV253B photocell was activated to record the time that the pigeon's head was in the food hopper recess. A 7-W, 28-VDC houselight located behind a 5-cm diameter circular aperture $2 \mathrm{~cm}$ from the right side of work panel and $2 \mathrm{~cm}$ from the floor provided general illumination during sessions. A ventilation fan and white noise generator provided ventilation and masked extraneous sound. A computer, located in an adjacent room, ran Med-PC IV® software to control the procedures described below and recorded session data.

\section{Procedure}

Following a short period of training in which the VI schedule was increased gradually, each pigeon was exposed to a concurrent-chained VI 60-s FR 10 schedule. This schedule was in effect throughout the experiment. The VI schedules were constructed from 10 intervals generated using the distribution described by Flesher and Hoffman (1962). To ensure that an equal number of terminal-link entries would occur and relative reinforcement rates would remain equivalent, entries were assigned using the method described by Stubbs and Pliskoff (1969), in which entries were assigned independently and randomly between each component.

Figure 1 shows a diagram of the concurrent chains schedule that was used throughout the experiment. Each session began with a 180-s blackout of the chamber. Then, the houselight was turned on and both response keys, each associated with an independent VI 60-s schedule, were transilluminated green. A 3-s change over delay (COD) was in effect such that a peck on the opposing key initiated a 3-s timer, after which, the next peck following $3.0 \mathrm{~s}$ was reinforced, if it 
was available. When the initial- link schedule requirement was met, both keys darkened and the appropriate terminal-link keylight was transilluminated. Pecks to the inactive, darkened key were without consequence. Following the tenth response on the active key, the hopper was activated. Breaking the photocell located inside the food hopper recess started a timer that kept the hopper activated until the assigned duration had lapsed, when it then deactivated. Hopper durations available in either terminal link varied as a function of the conditions described below. When the hopper was deactivated, the initial-link schedules again were in effect and both response keys were green. This process continued until all programed reinforcers were obtained. The experiment began with a baseline condition, in which the reinforcement duration following completion of either terminal link was $6 \mathrm{~s}$. After this, the conditions described below were examined in the order shown in Table 1. The independent variables were reinforcer duration (6 vs. $10 \mathrm{~s}$, and 2 vs. $6 \mathrm{~s}$ ) and the presence or absence of differential stimuli associated with different reinforcer durations. The total hopper access duration within each session was 192 s across conditions. This value was selected to maintain the pigeons at $80 \%$ of ad libitum body weight in each condition and control for differences in absolute reinforcer magnitude across conditions.

Unsignaled 10-s Duration (10sU). Reinforcer access was $6 \mathrm{~s}$ in one terminal link and 10 $\mathrm{s}$ in the other. There were 24 reinforcer deliveries per session in this condition.

Unsignaled 2-s Duration (2sU). Reinforcer access was $6 \mathrm{~s}$ in one terminal link and $2 \mathrm{~s}$ in the other. There were 48 reinforcer deliveries per session in this condition.

Signaled 10-s Duration (10sS). Each terminal link was associated with a different color response key; white for the 6-s reinforcer and blue for the 10-s. Reinforcer access was $10 \mathrm{~s}$ in 
one terminal link and $6 \mathrm{~s}$ in the other. There were 24 reinforcer deliveries per session in this condition.

Signaled 2-s Duration (2sS). Each terminal link was associated with a different color response key; white for the 6-s reinforcer and yellow for the 2-s. Reinforcer access were $6 \mathrm{~s}$ in one terminal link and $2 \mathrm{~s}$ in the other. There were 48 reinforcer deliveries per session in this condition.

Each condition was in effect for a minimum of 10 sessions and until absolute response rates in the initial links were stable according to the following criterion. First an average for the last six sessions was calculated. Next these six sessions were divided in to two groups of three (e.g. sessions one through three and sessions four through six) and the averages for these two groups were calculated. When the difference between each of the two 3-day averages and the 6session average was less than 3 responses per minute, the data were considered stable. Apart from a two-week break due to an equipment failure sessions generally occurred seven days a week at approximately the same time each day and ended after the specified number of reinforcer deliveries in each condition.

\section{Hopper Engagement}

\section{Results}

Figure 2 shows the average duration of hopper engagement per hopper presentation. This was calculated by taking the total hopper engagement duration and dividing by the number of hopper presentations for that alternative. There was some variability in hopper engagement between pigeons, however, hopper engagement was longer for the longer duration reinforcer than for the shorter duration reinforcer and this was consistent for each pigeon. There were no systematic differences in hopper engagement times between signaled and unsignaled reinforcer 
duration conditions. A scatter plot of hopper engagement times as a function of available hopper access is shown in Figure 3. Engagement was most variable during the 10-s hopper presentations and overlapped with the distribution of 6-s hopper presentations. A clear difference in engagement was observed between 2-s hopper and 6-s hopper presentations.

\section{Initial-Link Responding}

Figure 4 shows the choice proportions for the longer-duration reinforcer for each pigeon across all conditions. The mean proportions were calculated over the last 6 sessions in each condition. During the Unsignaled 10-s Duration (10sU) conditions and the Signaled 10-s Duration (10sS) conditions, a consistent preference for the 10-s reinforcer was observed only with Pigeon 17189. Preference for the 10-s reinforcer was observed for Pigeon 11718 during the initial $10 \mathrm{~s} U$ condition and during the $10 \mathrm{sS}$ condition, however failed to maintain this preference during the reversal to the $10 \mathrm{sU}$ condition. Preference was unchanged during the $10 \mathrm{~s} S$ condition across all pigeons. In the Unsignaled 2-s Duration (2sU) and Signaled 2-s Duration (2sS) conditions, there was a strong preference for the 6-s reinforcer for Pigeons 11718, 1104, and 847. There was no major difference in preference during the $2 \mathrm{sS}$ condition for condition.

Figure 5 shows the response rates in both initial links for the last six sessions of each condition. In this analysis, preference is defined as the initial link with the higher response rate. During the $10 \mathrm{sU}$ and $10 \mathrm{sS}$ conditions response rates were undifferentiated (e.g., Pigeon 11718) or were slightly higher for the initial link that terminated in the shorter duration reinforcer (e.g., Pigeons 1104 and 847). For Pigeon 17189 response rates were higher for the initial link that resulted in $10 \mathrm{~s}$ of hopper access compared to the initial link that led to $6 \mathrm{~s}$ of hopper access across the $10 \mathrm{sU}$ and $10 \mathrm{sS}$ conditions. The inclusion of signaled terminal links in the $10 \mathrm{sS}$ condition decreased (e.g., Pigeon 847) or had little effect on initial-link response rates. 
In the $2 \mathrm{sU}$ and $2 \mathrm{sS}$ Conditions, response rates were generally higher for the initial link that resulted in $6 \mathrm{~s}$ of hopper access versus the link that resulted in $2 \mathrm{~s}$ of hopper access. The inclusion of the signaled terminal link did not affect preference for the longer duration alternative. Initial-link response rates decreased with Pigeon 17189 during the signaled condition relative to the $2 \mathrm{sU}$ conditions. In the reversal to the $2 \mathrm{sU}$ condition, initial-link response rates were similar to those in the prior condition $2 \mathrm{sU}$ condition.

Figure 6 shows initial-link response rates for the first six sessions and last six sessions of each condition. Although the number of sessions in each condition significantly varied see Table 1), preferences for one alternative relative to the other rapidly developed during the first six sessions. Transitions between signaled and unsignaled conditions (e.g., 10sS and 10sU) were more variable than transitions between conditions in which the reinforcer duration varied (e.g., 10sU and 2sU).

Figure 7 shows the magnitude of preference for the longer duration reinforcer relative to the shorter duration reinforcer. This analysis uses the differences in the area under the curve $(\mathrm{AuC})$ as an index of preference. First, the area under each curve was calculated by taking the area of a trapezoid (i.e., Area $=(($ base $1+$ base 2$) / 2) \times$ height $)$ formed by each adjacent data path and the $\mathrm{x}$ axis. Then, the area of the curve associated with the initial link that terminated in the shorter duration reinforcer was subtracted from the area of the curve associated with the initial link that terminated in the longer duration reinforcer. The greater the difference in areas in the positive direction denotes a greater preference for the longer duration reinforcer. Negative values indicate a preference for the shorter duration reinforcer. During the 10sU and 10sS conditions, preferences for the shorter duration reinforcer (i.e., $6 \mathrm{~s}$ hopper access) were found with Pigeons 847 and 1104. There was no clear preference for one reinforcer duration over the 
other for the first 10sU condition and the 10sS for Pigeon 11718, however, during the reversal to the $10 \mathrm{sU}$ condition, there was a slight preference for the shorter duration reinforcer. In the $2 \mathrm{sU}$ and $2 \mathrm{sS}$ conditions, there were clear preferences for the initial link that led to the $6 \mathrm{~s}$ reinforcer access for Pigeons 11718, 1104, and 847. For Pigeon 17189, there was a slight preference for the 2-s reinforcer.

To isolate the effect of the reinforcer duration on initial-link responding, relative response rates were calculated for each initial link. Relative response rates were calculated by dividing each session's response rate by the average baseline response rate and are shown in Figure 8. Relative rates generally changed as a function of the reinforcer duration presented on that key. The largest increase in relative response rates was observed with Pigeon 11718 during the 10sU and 10 sS conditions, however this effect did not occur with the other pigeons. In the $2 \mathrm{sS}$ and $2 \mathrm{sU}$ conditions, relative rates generally decreased on both initial links, however the largest decreased was observed in the initial link that terminated in the 2-s reinforcer. Generally, there was no difference in relative rates between signaled and unsignaled conditions.

\section{Terminal-Link Responding}

Terminal-link response rates for the last six sessions for all conditions are shown in Figure 9. During the 10sU conditions, response rates in the terminal links were undifferentiated for Pigeons 11718 and 847. In the 10sS condition, terminal-link response rates which led to the longer duration reinforcer decreased for Pigeons 11718 and 847. Terminal-link response rates for Pigeons 1104 and 17189 were unaffected by the inclusion of the differential terminal-link stimuli.

During the $2 \mathrm{~s} U$ conditions response rates were undifferentiated for Pigeons 11718, 847, and 17189. For Pigeon 1104, however, response rates were consistently higher for the terminal 
link that led to the longer duration reinforcer. In the $2 \mathrm{sS}$ condition, response rates were differentiated in favor of the longer-duration reinforcer for Pigeon 11718. Response rates remained undifferentiated for Pigeons 17189, 847, and 1104 during the 2 sS condition. I would end this with a general statement about how response rates were not differentiated by reinforcer duration, even in the terminal link, and even though the pigeons ate differentially (or at least entered the hopper differentially).

\section{Postreinforcement Pauses}

Figure 9 shows the postreinforcement pauses across all conditions. Pausing was consistently longer following the delivery of a shorter-duration reinforcer for all pigeons during the $2 \mathrm{sS}$ and $2 \mathrm{sU}$ conditions. In the $10 \mathrm{sS}$ and $10 \mathrm{sU}$ conditions, pausing was longer following the delivery of the 10-s reinforcer for Pigeon 1104. In the second 10sU condition, pausing was longer following the delivery of the 10-s reinforcer for Pigeons 847. For Pigeons 11718 and 17189 PRPs were longer following the delivery of shorter-duration reinforcers across all conditions.

\section{Discussion}

The purpose of the current experiment was to examine the effects of stimuli correlated with specific reinforcer durations on preference. There were preferences for the longer-duration reinforcer, however, the addition of differential terminal-link stimuli did not potentiate preference relative to the absence of these stimuli. Preference for the longer-duration reinforcer was greater during the 2- vs. 6-s reinforcer durations compared to the 6-vs. 10-s durations, indicating that the relative differences between reinforcer durations may play an important role in the control of preference. The relation between hopper engagement and preference suggests that longer eating times do not predict preference in all cases. 
Bonem and Crossman (1988) suggested that the effects of reinforcer duration might be enhanced by associating differential stimuli with different reinforcer durations. This was achieved in two ways in the current experiment. First, the effects of reinforcer duration were assessed in a concurrent arrangement, which allowed the organism to contact differing reinforcer durations within sessions. Additionally, terminal-link stimuli correlated with specific reinforcer durations also were assessed. The following sections explore the influence of signaled reinforcer durations and, more broadly, reinforcer duration on preference. Throughout the discussion, signaled refers to cases in which terminal-link stimuli are differential, whereas unsignaled refers to terminal-link stimuli that are the same.

\section{The Effects of Differential Terminal-Link Stimuli on Preference}

As noted in the Literature Review, when reinforcers are of different durations, their duration is discriminable only at some time after their onset. When multiple stimuli are presented simultaneously, some of those stimuli come to exert more control over behavior than do others, dependent on their relative differences in either intensity or modality (Pavlov, 1960; Kamin, 1969; Mackintosh, 1976). Given the invariant stimulus conditions associated with reinforcer onset in most operant conditioning preparations, including the present one, the reinforcer duration may be "overshadowed" by the stimulus conditions in effect at reinforcer onset, thus potentially neutralizing or at least greatly attenuating the impact of such duration on responding. That is, when a food hopper is presented, it is always accompanied by the sound of the hopper and the hopper light, irrespective of the programmed duration of access to it. The present results suggest that the presence of a signal indicating the upcoming reinforcer duration onset does not potentiate preference relative to undifferentiated terminal links. This is inconsistent with Ploog's (2001) finding that adding terminal-link stimuli differentially 
associated with different reinforcer durations did potentiate preference relative to the absence of differential terminal-link stimuli.

To control for differences in reinforcement rate between alternatives, that is, to ensure equal exposure to both terminal links, the Stubbs and Pliskoff (1969) procedure was used to control terminal-link entries in the current procedure. This procedure ensures that both alternatives are contacted equally and controls for the effects of differences in reinforcement rate that may confound preference (see Davison \& McCarthy, 1988, for a discussion of the relation between preference and reinforcement rates). There is some debate as to the effects of independent and dependent scheduling of terminal-link entries on preference in a concurrentchains procedure. It has been suggested by some that dependent scheduling reduces the degree or extent of preference for one alternative over another in a concurrent-chains arrangement (Davison \& McCarthy, 1988; Snyderman, 1983). The empirical evidence, however, shows that dependent scheduling potentiates the control of initial-link responding by the consequences delivered at the end of terminal link (hereafter, sensitivity) (Mattson, Hucks, Grace, \& McLean, 2010).

The use of the dependent-scheduling procedure prevents the development of exclusive preference of one alternative over another. Ploog (2001), for example, using independent scheduling of terminal-link entries, reported that four of 12 pigeons responded almost exclusively for the initial link that was correlated with the longer-duration reinforcer. The dependent scheduling of terminal-link entries may have attenuated the development of extreme preferences in the current procedure. If terminal-link entries could be entered independently, this may have resulted in preferences that were due to factors other than reinforcer magnitude (e.g., more responding on one key due to its position and not its outcome). Using dependent 
scheduling of terminal-link entries may have reduced any differential effects of including differential terminal-link stimuli. A direct comparison between independently and dependently scheduled terminal-link entries, however, would be necessary to identify the effects of this arrangement on preference between reinforcers of different durations.

Conflicting effects of differential terminal-link stimuli on initial-link responding have been reported. Mattson et al. (2010) reported that sensitivity to the immediacy of reinforcer delivery and the probability of reinforcement was greater when these variables were in unsignaled relative to signaled conditions. Based on Mattson et al., it could be argued that including a terminal-link stimulus that specifies its outcome reduces the observed effects on initial-link responding due to the parameters of reinforcement delivered in the terminal links. When Ploog (2001), however, included differential-terminal link stimuli, he found enhanced preference for the longer-duration reinforcer. In the current experiment, including a differential terminal-link stimulus did not appear to change preference relative to the preceding unsignaled condition. Thus, the results of the current procedure replicate neither Mattson et al., nor Ploog (2001).

In the present experiment, the physical arrangement of the concurrent-chains procedure may have attenuated the effects of signaled reinforcer durations on preference. Aside from pairing a specific terminal-link stimulus with each duration each side was consistently correlated with that specific reinforcer duration. Thus, the side may have functioned as a discriminative stimulus and overshadowed visual stimuli. Williams and Fantino (1978) provide some evidence suggesting such an effect. In their analysis of signaled versus unsignaled delays, preference for the shorter delay increased during signaled conditions. When the delays were no longer 
signaled, preference remained unchanged from the signaled condition, thus indicating that side may have functioned as a discriminative stimulus.

\section{Effects of Reinforcer Duration on Preference}

Three of four pigeons in the $2 \mathrm{sU}$ and $2 \mathrm{sS}$ conditions preferred the longer-duration reinforcer, demonstrating that the reinforcer presented at the end of the terminal link controlled initial-link responding in these conditions. These findings from the $2 \mathrm{sU}$ and $2 \mathrm{sS}$ conditions are similar to those reported by Ploog (2001) and Snyderman (1983). That is, when presented with a 2-s vs. 6-s reinforcer, preference for the longer-duration reinforcer is observed.

The data in Figure 6 show the preferences occurred relatively early in each condition and persisted throughout each condition. The early development of preference for the longerduration reinforcer during $2 \mathrm{sU}$ and $2 \mathrm{sS}$ conditions contradicts the findings reported by Ploog (2001), who reported preference for longer-duration reinforcers took 5 to 20 sessions for some pigeons. The rapid and persistent preference for the longer-duration reinforcer observed during the $2 \mathrm{sU}$ and $2 \mathrm{sS}$ conditions also contradicts the notion that the effects of reinforcer magnitude may be transitory (e.g., Keesey \& Kling, 1961).

Only one of four pigeons preferred the longer-duration reinforcer $(10 \mathrm{~s})$ during the $10 \mathrm{sU}$ and $10 \mathrm{sS}$ conditions. Initial-link responding was also more variable during the $10 \mathrm{sU}$ and $10 \mathrm{sS}$ conditions relative to the $2 \mathrm{sU}$ and $2 \mathrm{sS}$ conditions (see Appendix A). Ploog (2001) reported that preference for the longer-duration reinforcer was not observed when presented with 3-s or 6-s reinforcers when terminal links were unsignaled. This finding indicates that preferences may be determined in part by the relative difference of the reinforcer durations that are presented.

Relative versus absolute temporal difference in reinforcer duration may play an important role in accounting for the differences in preference observed when pigeons were presented with 
either 2-s vs. 6-s or 6-s vs. 10-s reinforcer durations. Pigeons can discriminate temporal stimuli of different durations (Stubbs, 1968). Using a match-to-sample conditional-discrimination procedure in which the basis of choices by pigeons was the duration of a sample stimulus, discriminations were a function of the logarithmic difference between the two sample stimuli and not the absolute difference. Although the absolute difference between $2 \mathrm{~s}$ vs. $6 \mathrm{~s}$ is the same as 6 s vs. $10 \mathrm{~s}$, the relative difference between $2 \mathrm{~s}$ vs. $6 \mathrm{~s}$ is thrice as much as the relative difference between $10 \mathrm{~s}$ vs. $6 \mathrm{~s}$. Because the temporal control of the reinforcer is assumed to differentially control behavior, this relative difference may account for why preference for the longer-duration reinforcer was not observed during the 10sS and 10sU conditions. A condition in which pigeons were presented with reinforcer durations of $6 \mathrm{~s}$ and $18 \mathrm{~s}$, would be needed to assess whether preferences are determined by the relative difference versus the absolute differences in reinforcer duration. The issue of within-session satiation at longer-reinforcer durations (e.g., $18 \mathrm{~s}$ or more), however, may restrict the range of durations that can be studied with any chance of obtaining behavioral differences when relative differences in reinforcer durations are used as compared to absolute differences. Shorter sessions could be conducted to prevent within-session satiation, however these sessions would provide a limited number of observations, which in turn, would erode the reliability and validity of the data obtained.

\section{Postreinforcement Pauses and Terminal-Link Responding}

Both terminal-link response rates and postreinforcement pauses are differentially affected by different reinforcer durations (Bonem \& Crossman, 1988). In this experiment, however, the different reinforcer durations did not yield differential effects on PRPs. In cases in which discriminative stimuli are present, PRPs on FR schedules are a function of the previous and upcoming reinforcer durations (Perone \& Courtney, 1992). Given that terminal-link entries were 
randomly assigned and there were no discriminative stimuli that signaled upcoming reinforcer durations during the initial links, these factors may account for why PRPs tended to be variable in the current experiment.

Differential reinforcer durations produced idiosyncratic effects on terminal-link response rates. Neuringer (1967) reported that terminal-link response rates decreased as a function of the reinforcer duration that was delivered at the end of that link, which is consistent with the effects of reinforcer duration on FI responding (Staddon, 1970). Ploog (2001), who used VI schedules in the terminal links, reported that terminal-link responding tended to be higher in the link that led to the longer-duration reinforcer. Thus, it appears that terminal-link response rates are partially controlled by the schedule of reinforcement that is used. The use of an FR 10 schedule in the terminal links of the current experiment, may account for the inconsistent effects of reinforcer duration on terminal link-response rates. Powell (1969), for example, reported that reinforcer duration did not systematically affect responses rates on FR schedules. It may be possible that if an FI or VI schedules were used in the terminal links, systematic effects of reinforcer duration on terminal-link response rates may have been observed.

\section{Conclusion}

It has been suggested that reinforcer duration may not be functionally equivalent to other manipulations of reinforcer magnitude such as the number of items or the concentration of a substance (Bonem \& Crossman, 1988). One reason could be that reinforcer duration is not discriminable until some period of time after its onset. The current experiment attempted to enhance the discriminative control of reinforcer duration on preference by signaling duration prior to the actual reinforcer onset. The results, however, did not show such an effect nor were they consistent with previous findings (e.g., Mattson et al., 2010; Ploog, 2001). The failure to 
obtain distinct effects with the use of differential terminal-link stimuli on initial-link responding in the current experiment suggests that other factors, such as the relative difference in reinforcer duration, may exert more control than the stimuli presented during the terminal links. Thus, rendering the inclusion of the differential terminal-link stimuli unnecessary.

The present results do offer some support for the observation that relative differences in reinforcer durations may be functionally related to preference. When it comes to the effects of correlating stimuli with specific reinforcer duration, the present results offer no systematic support that their inclusion affects preference for longer-duration reinforcers. Preference tended to vary as a function of reinforcer duration rather than, as noted above, a function of the inclusion of stimuli correlated with specific reinforcer durations. Ultimately, the present results combine with previous findings of inconsistent effects of reinforcer duration on operant responding to suggest that duration is a far more complex variable than it appears. 


\section{References}

Autor, S. M. (1969). The strength of conditioned reinforcers as a function of frequency and probability of reinforcement. In D. P. Hendry (Ed.), Conditioned Reinforcement. Homewood, Ill: The Dorsey Press.

Baum, W. M., \& Rachlin, W. M. (1969). Choice and time allocation. Journal of the Experimental Analysis of Behavior, 12, 861-874. doi:10.1901/jeab.1969.12-861

Bonem, M., \& Crossman, E. K. (1988). Elucidating the effects of reinforcement magnitude. Psychological Bulletin, 104, 348-362. doi:10.1037/0033-2909.104.3.348

Brownstein, A. J. (1971). Concurrent schedules of response independent reinforcement: Duration of a reinforcer stimulus. Journal of the Experimental Analysis of Behavior, 15, 211-214. doi:10.1901/jeab.1971.15-211

Catania, A. C. (1963). Concurrent performances: A baseline for the study of reinforcement magnitude. Journal of the Experimental Analysis of Behavior, 6, 299-300. doi:10.1901/jeab.1963.6-299

Davison, M., \& McCarthy, D. (1988). The Matching Law: A Research Review. Hillsdale, NJ: Lawrence Erlbaum Associates

Duncan, B., \& Fantino, E. (1970). Choice for periodic schedules of reinforcement. Journal of the Experimental Analysis of Behavior, 14, 73-86. doi:10.1901/jeab.1970.14-73

Epstein, R. (1985). Amount consumed varies as a function of feeder design. Journal of the Experimental Analysis of Behavior, 44, 121-125. doi:10.1901/jeab.1985.44-121

Fantino, E. (1977). Choice and conditioned reinforcement. In W. K. Hong \& J. E. R. Staddon (Eds.). Operant behavior: Areas of research and application (pp. 313-339). New York: Prentice Hall. 
Fantino, E., Squires, N., Delbrück, N., \& Peterson, C. (1972). Choice behavior and the accessibility of the reinforcer. Journal of the Experimental Analysis of Behavior, 18, 3543. doi:10.1901/jeab.1972.18-35

Fleshler, M., \& Hoffman, H. S. (1962). A progression for generating variable-interval schedules. Journal of the Experimental Analysis of Behavior, 5, 529-530. doi:10.1901/jeab.1962.5-529

Green, L., \& Rachlin, H. (1977). Pigeons' preference for stimulus information: Effects of amount of information. Journal of the Experimental Analysis of Behavior, 27, 255-263. doi:10.1901/jeab.1977.27-255

Ito, M., \& Asaki, K. (1982). Choice behavior of rats in a concurrent chains schedule: Amount and delay of reinforcement. Journal of the Experimental Analysis of Behavior, 37, 383392. doi:10.1901/jeab.1982.37-383

Jenkins, W. O., \& Clayton, F. L. (1949). Rate of responding and amount of reinforcement. Journal of Comparative and Physiological Psychology, 42(3), 174-181. doi: $10.1037 / \mathrm{h} 0055036$

Kamin, L. J. (1969). Predictability, surprise, attention, and conditioning. In B. Campbell \& R. Church (Eds.). Punishment and aversive behavior. New York: Appelton-Century-Crofts

Keesey, R. E., \& Kling, L. W. (1961). Amount of reinforcement and free-operant responding. Journal of the Experimental Analysis of Behavior, 4, 125-132. doi:10.1901/jeab.1961.4-125

Lendenmann, K. W., Myers, D. L., \& Fantino, E. (1982). Effects of reinforcer duration on responding in two-link chained interval schedules. Journal of the Experimental Analysis of Behavior, 37, 217-222. doi:10.1901/jeab.1982.37-217 
Mackintosh, N. J. (1976). Overshadowing and stimulus intensity. Animal Learning and Behavior, 4(2), 186-192. doi:10.3758/bf03214033

Mattson, K. M., Hucks, A., Grace, R. C., \& McLean A. P. (2010). Signaled and unsignaled terminal links in concurrent chains I: Effects of reinforcer probability and immediacy. Journal of the Experimental Analysis of Behavior, 94, 327-352.

doi:10.1901/jeab.2010.94-327

Mazur, J. E., \& Fantino, E. (2014). Choice. In F. K. McSweeney and E. S. Murphy (Eds.), The Wiley Blackwell Handbook of Operant and Classical Conditioning (195-220). Malden, MA: Wiley Blackwell

Moore, J. (1979). Choice and number of reinforcers. Journal of the Experimental Analysis of Behavior, 32, 51-65. doi:10.1901/jeab.1979.32-51

Neuringer, A. J. (1967). Effects of reinforcement magnitude on choice and rate responding. Journal of the Experimental Analysis of Behavior, 10, 417-424. doi:10.1901/jeab.1967.10-417

Pavlov, I. P. (1960). Conditioned reflexes: An investigation of the physiological activity of the cerebral cortex. New York: Dover Publications.

Powell, R. W. (1969). The effect of reinforcement magnitude upon responding under fixed-ratio schedules. Journal of the Experimental Analysis of Behavior, 12, 605-608. doi:10.1901/jeab.1969.12-605

Ploog, B. O. (2001). Effects of primary reinforcement on pigeon's initial-link responding under a concurrent-chains schedule with nondifferential terminal links. Journal of the Experimental Analysis of Behavior, 76, 75-94. doi:10.1901/jeab.2001.76-75 
Perone, M., \& Courtney, K. (1992). Fixed-ratio pausing: Joint effects of past reinforcer magnitude and stimuli correlated with upcoming magnitude. Journal of the Experimental Analysis of Behavior, 57, 33-46. doi:10.1901/jeab.1992.57-33

Powell, R. W. (1969). The effect of reinforcement magnitude upon responding under fixed-ratio schedule. Journal of the Experimental Analysis of Behavior, 12, 605-608. doi:10.1901/jeab.1969.12-605

Shettleworth, S., \& Nevin, J. A. (1965). Relative rate of response and relative magnitude of reinforcement in multiple schedules. Journal of the Experimental Analysis of Behavior, 8, 199-202. doi:10.1901/jeab.1965.8-199

Snyderman, M. (1983). Delay and amount of reward in a concurrent chain. Journal of the Experimental Analysis of Behavior, 39, 437-447. doi:10.1901/jeab.1983.39-437

Spetch, M. L., Belke, T. W., Barnet, R. C., Dunn, R., \& Pierce, W. D. (1990). Suboptimal choice in a percentage-reinforcement procedure: Effects of signaled condition and terminal-link length. Journal of the Experimental Analysis of Behavior, 53, 219-234. doi:10.1901/jeab.1990.53-219

Spetch, M. L., \& Dunn, R. (1987). Choice between reliable and unreliable outcomes: Mixed percentage-reinforcement in concurrent chains. Journal of the Experimental Analysis of Behavior, 47, 57-72. doi:10.1901/jeab.1987.47-57

Staddon, J. E. R (1970). Effect of reinforcement duration on fixed-interval responding. Journal of the Experimental Analysis of Behavior, 13, 9-11. doi:10.1901/jeab.1970.13-9

Stubbs, D. A., \& Pliskoff, S. S. (1969). Concurrent responding with fixed relative rate of reinforcement. Journal of the Experimental Analysis of Behavior, 12, 887-895. doi:10.1901/jeab.1969.12-887 
Stubbs, A. (1968). The discrimination of stimulus duration by pigeons. Journal of the Experimental Analysis of Behavior, 11, 223-238. doi:10.1901/jeab.1968.11-223

Williams, B. A. (1994). Conditioned reinforcement: Experimental and theoretical issues. The Behavior Analyst, 17, 261-285.

Williams, B. A., \& Fantino, E. (1978). Effects of choice of reinforcement delay and conditioned reinforcement. Journal of the Experimental Analysis of Behavior, 29, 77-86.

doi:10.1901/jeab.1978.29-77 
Table 1

Order of Experiment Conditions

\begin{tabular}{|c|c|c|c|c|}
\hline Pigeon & $\begin{array}{c}\text { Number of } \\
\text { Sessions }\end{array}$ & $\begin{array}{l}\text { Experimental } \\
\text { Condition }\end{array}$ & $\begin{array}{c}\text { Hopper } \\
\text { duration (s) }\end{array}$ & $\begin{array}{c}\text { Terminal link } \\
\text { Stimuli }\end{array}$ \\
\hline & 13 & Baseline & 6,6 & Red, Red \\
\hline \multirow{6}{*}{11718} & 14 & $10 \mathrm{sU}$ & 10,6 & Red, Red \\
\hline & 43 & $10 \mathrm{sS}$ & 10,6 & Blue, White \\
\hline & 20 & $10 \mathrm{sU}$ & 10,6 & Red, Red \\
\hline & 21 & $2 s U$ & 2,6 & Red, Red \\
\hline & 18 & $2 \mathrm{sS}$ & 2,6 & Yellow, White \\
\hline & 32 & $2 \mathrm{sU}$ & 2,6 & Red, Red \\
\hline \multirow[t]{7}{*}{847} & 12 & Baseline & 6,6 & Red, Red \\
\hline & 15 & $10 \mathrm{sU}$ & 6,10 & Red, Red \\
\hline & 60 & $10 \mathrm{sS}$ & 6,10 & White, Blue \\
\hline & 32 & $10 \mathrm{sU}$ & 6,10 & Red, Red \\
\hline & 12 & $2 \mathrm{sU}$ & 6,2 & Red, Red \\
\hline & 20 & $2 \mathrm{sS}$ & 6,2 & White, Yellow \\
\hline & 17 & $2 \mathrm{sU}$ & 6,2 & Red, Red \\
\hline \multirow[t]{7}{*}{17189} & 13 & Baseline & 6,6 & Red, Red \\
\hline & 14 & $2 \mathrm{sU}$ & 6,2 & Red, Red \\
\hline & 26 & $2 s S$ & 6,2 & Yellow, White \\
\hline & 15 & $2 \mathrm{sU}$ & 6,2 & Red, Red \\
\hline & 13 & $10 \mathrm{sU}$ & 6,10 & Red, Red \\
\hline & 33 & $10 \mathrm{sS}$ & 6,10 & Blue, White \\
\hline & 15 & $10 \mathrm{sU}$ & 6,10 & Red, Red \\
\hline \multirow[t]{7}{*}{1104} & 19 & Baseline & 6,6 & Red, Red \\
\hline & 20 & $2 \mathrm{sU}$ & 2,6 & Red, Red \\
\hline & 29 & $2 s S$ & 2,6 & White, Yellow \\
\hline & 27 & $2 \mathrm{sU}$ & 2,6 & Red, Red \\
\hline & 21 & $10 \mathrm{sU}$ & 10,6 & Red, Red \\
\hline & 30 & $10 \mathrm{sS}$ & 10,6 & White, Blue \\
\hline & 31 & $10 \mathrm{sU}$ & 10,6 & Red, Red \\
\hline
\end{tabular}

Note. Condition order, experimental condition, hopper durations, and terminal link stimuli for each pigeon in each condition. In columns that show pairs of values, the left value denotes the left link and the right value for the right link. 

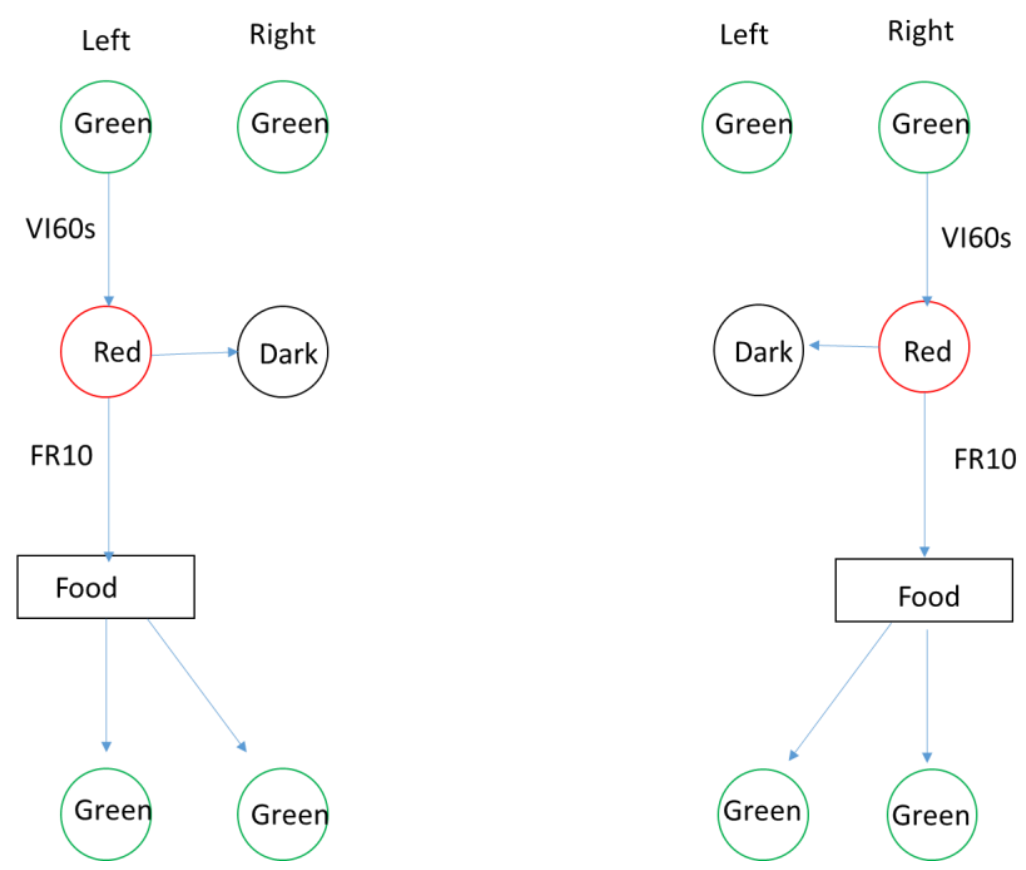

Figure 1. A diagram illustrating the experimental procedure that was used during the experiment. In the initial links a variable interval (VI) 60s schedule of reinforcement was in effect for both keys. When the initial-link schedule requirement was met, entry into one of two mutually exclusive two terminal links occurred. The inactive key was inactivated during this period. When the terminal-link schedule requirement was met, the reinforcer was delivered. Following the delivery of the reinforcer the initial links were reinstated. Adapted from Fantino (1977). 


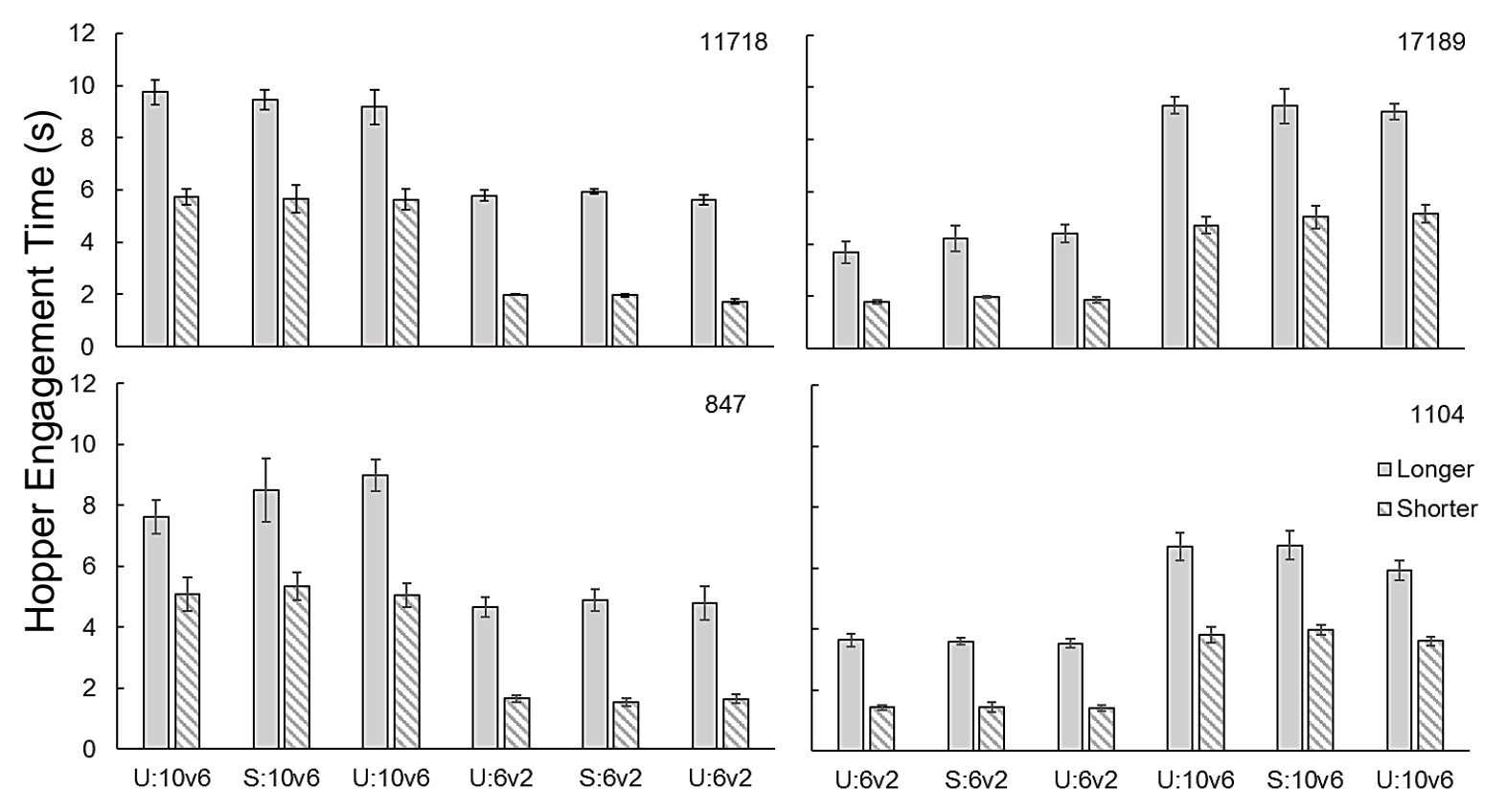

Figure 2. Average time engaged with hopper per hopper presentation during the last six sessions of each condition. The light grey bars represent the longer-duration hopper access and the shaded bars represent the shorter-duration access. Error bars denote one standard deviation. 


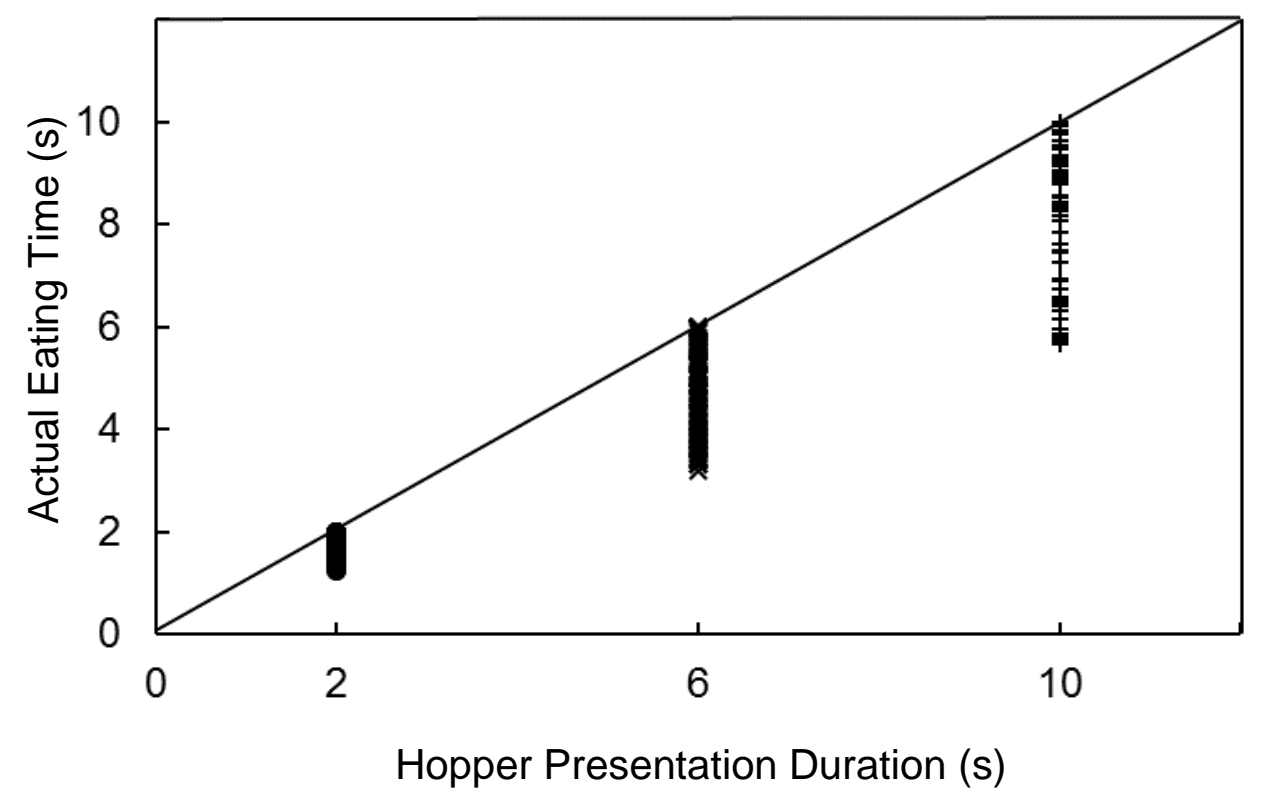

Figure 3. Distribution of eating times aggregated for all four pigeons for the 2, 6, and 10 seconds of reinforcer access. The horizontal line denotes maximum amount of time the hopper was presented each time during each presentation. 


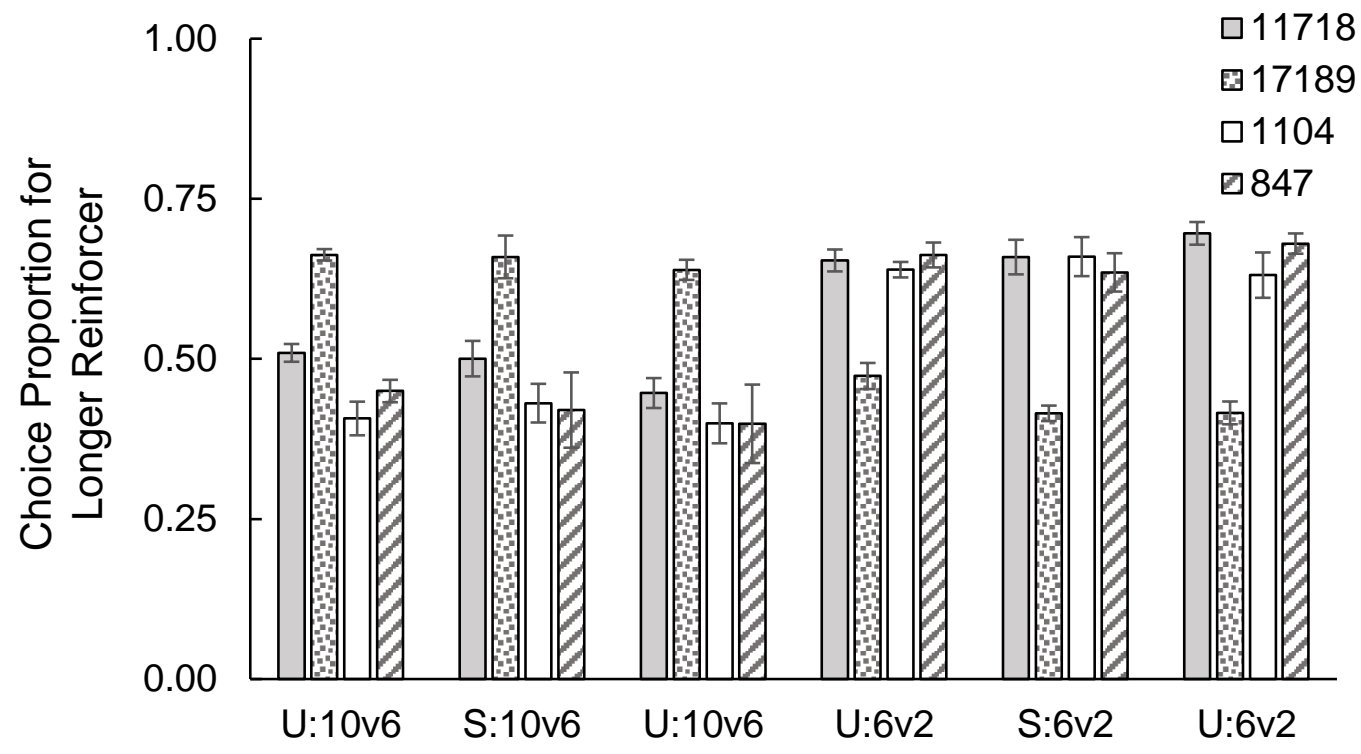

Figure 4. Mean choice proportion for the longer-duration reinforcer in each condition. The error bars indicate one standard deviation. 


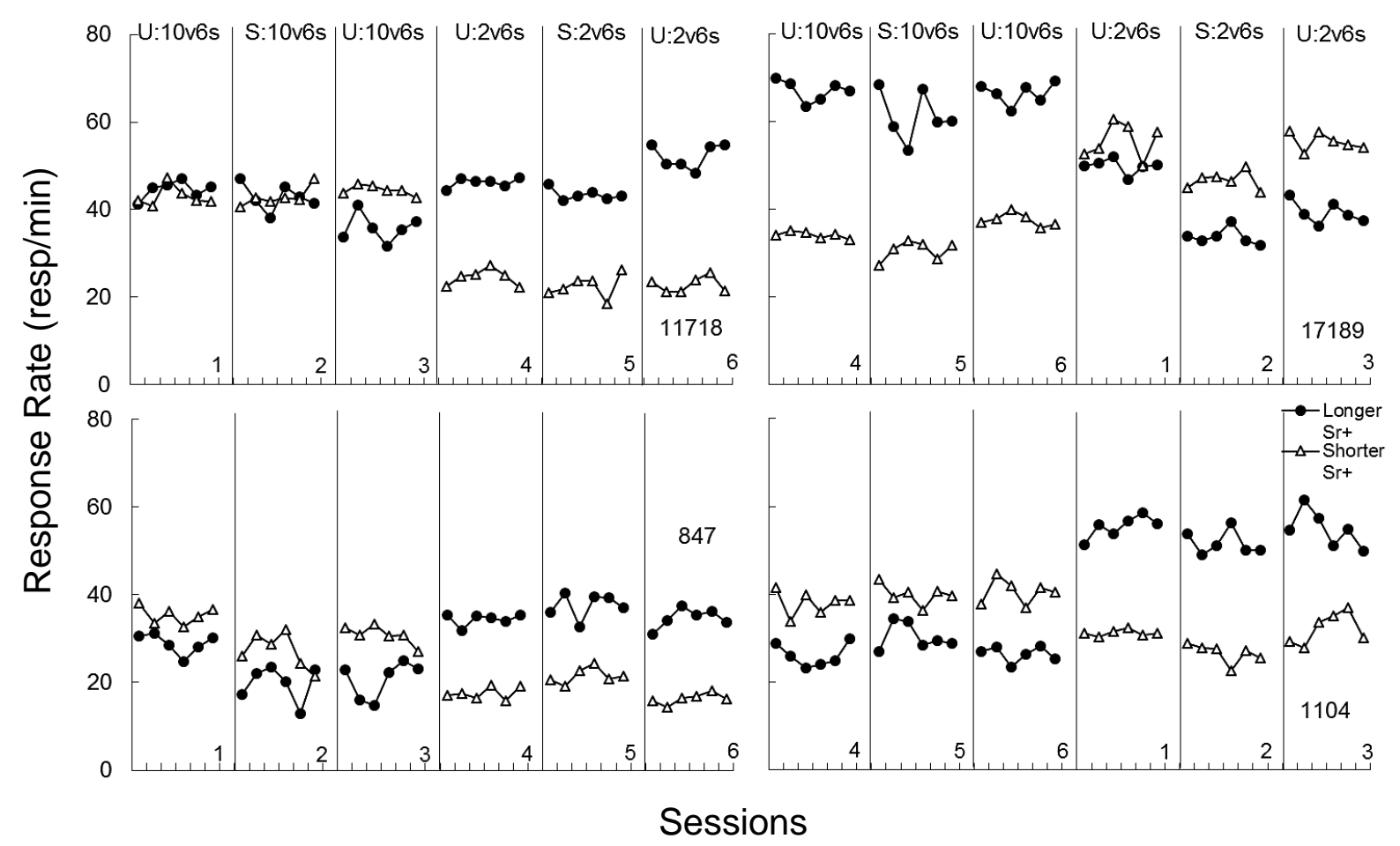

Figure 5. Initial-link responding during the last six sessions of each condition. The circle data path represents the initial link that led to the longer-duration reinforcer and the open triangles represent the response rates for the initial link that led to the shorter-duration reinforcer. The numerals in the bottom represent the order of each condition. 


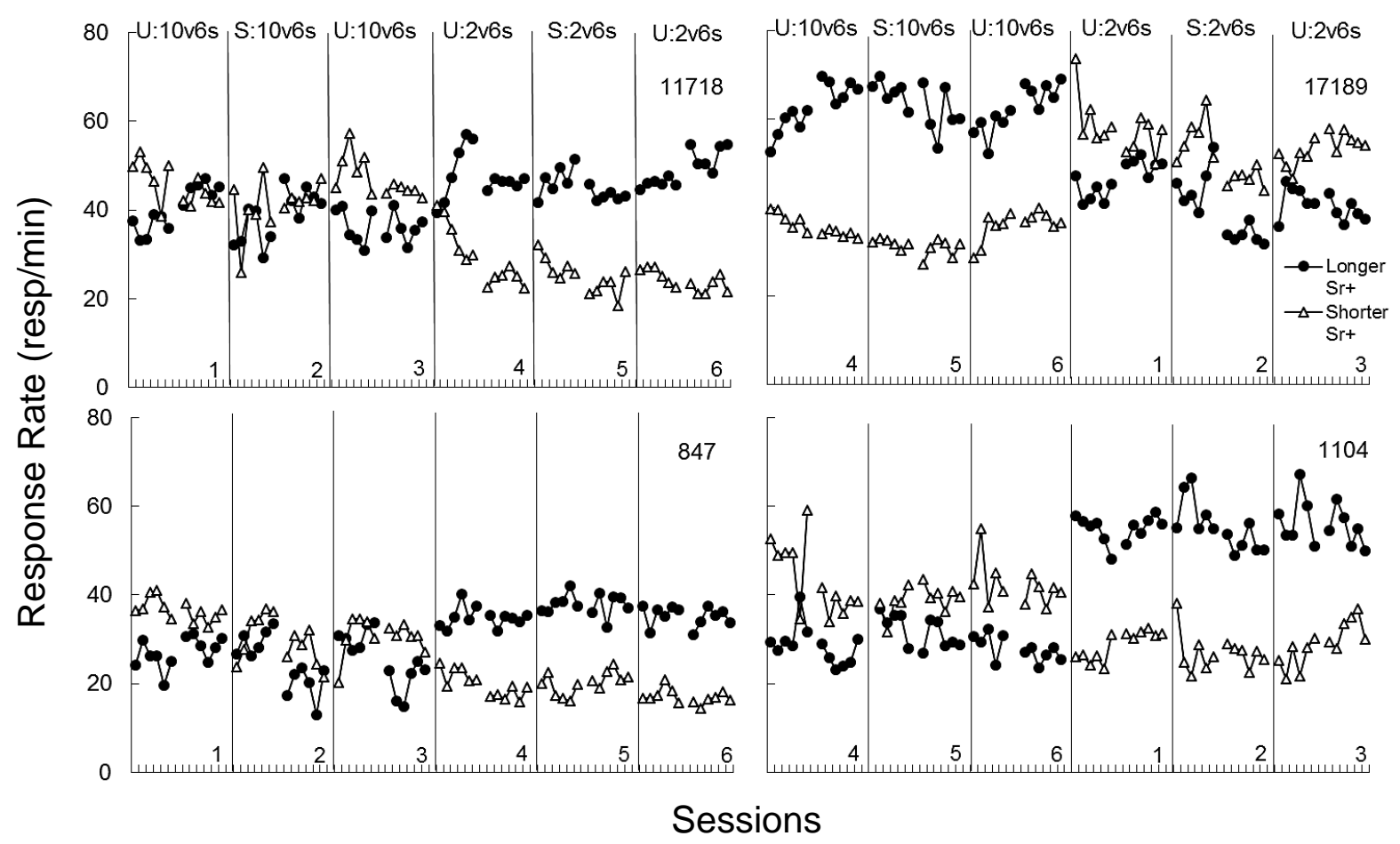

Figure 6. Initial-link response rates for the first six and last six sessions for each condition. The circle data path represents the initial link that led to the longer-duration reinforcer and the open triangles represent the response rates for the initial link that led to the shorter-duration reinforcer 


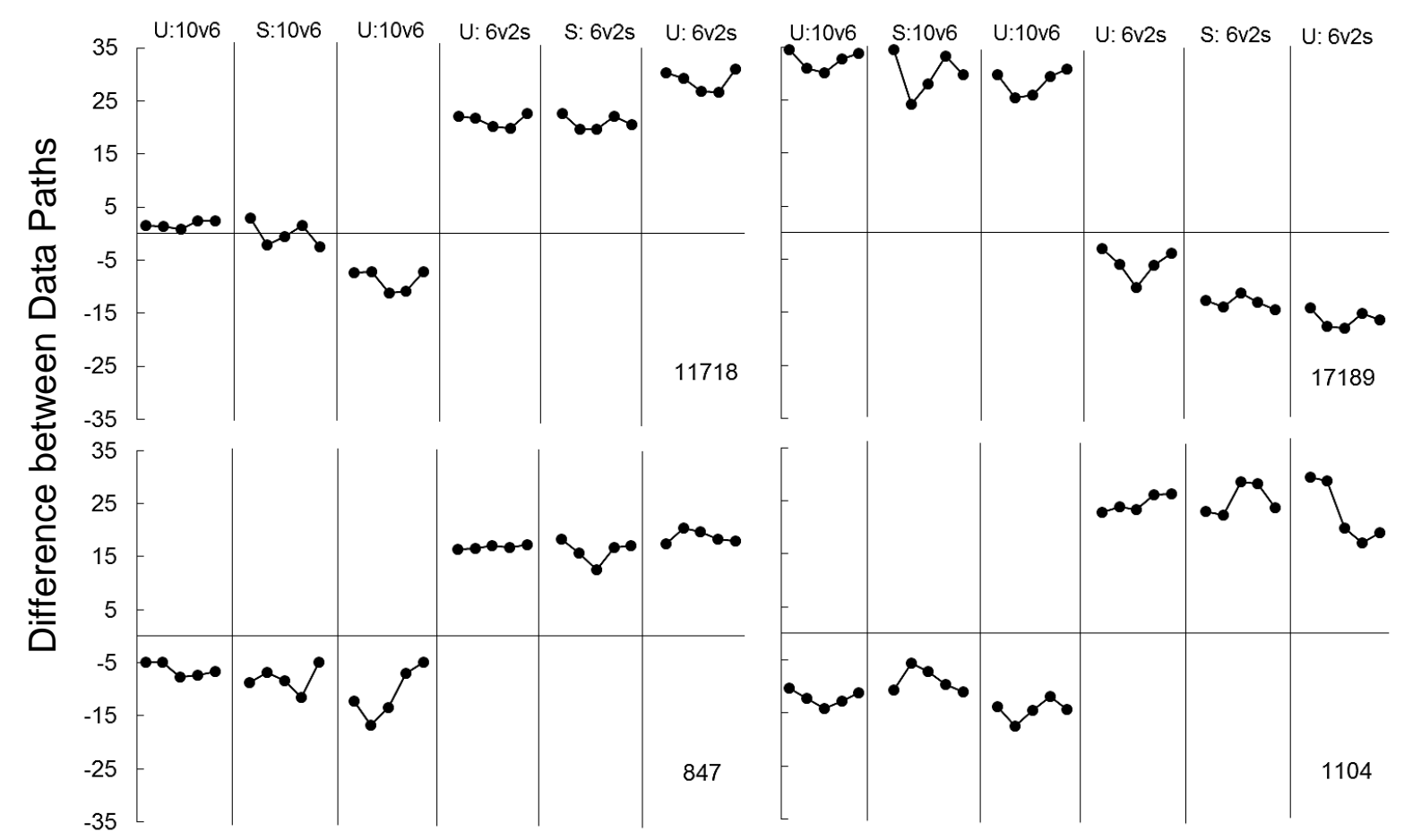

Sessions

Figure 7. Difference in initial link response rates. This graph depicts the difference in the area between the initial link that terminated with the longer-duration reinforcer and the initial link that terminated in the shorter-duration reinforcer. The greater the difference, the greater the preference for the longer-duration reinforcer. 


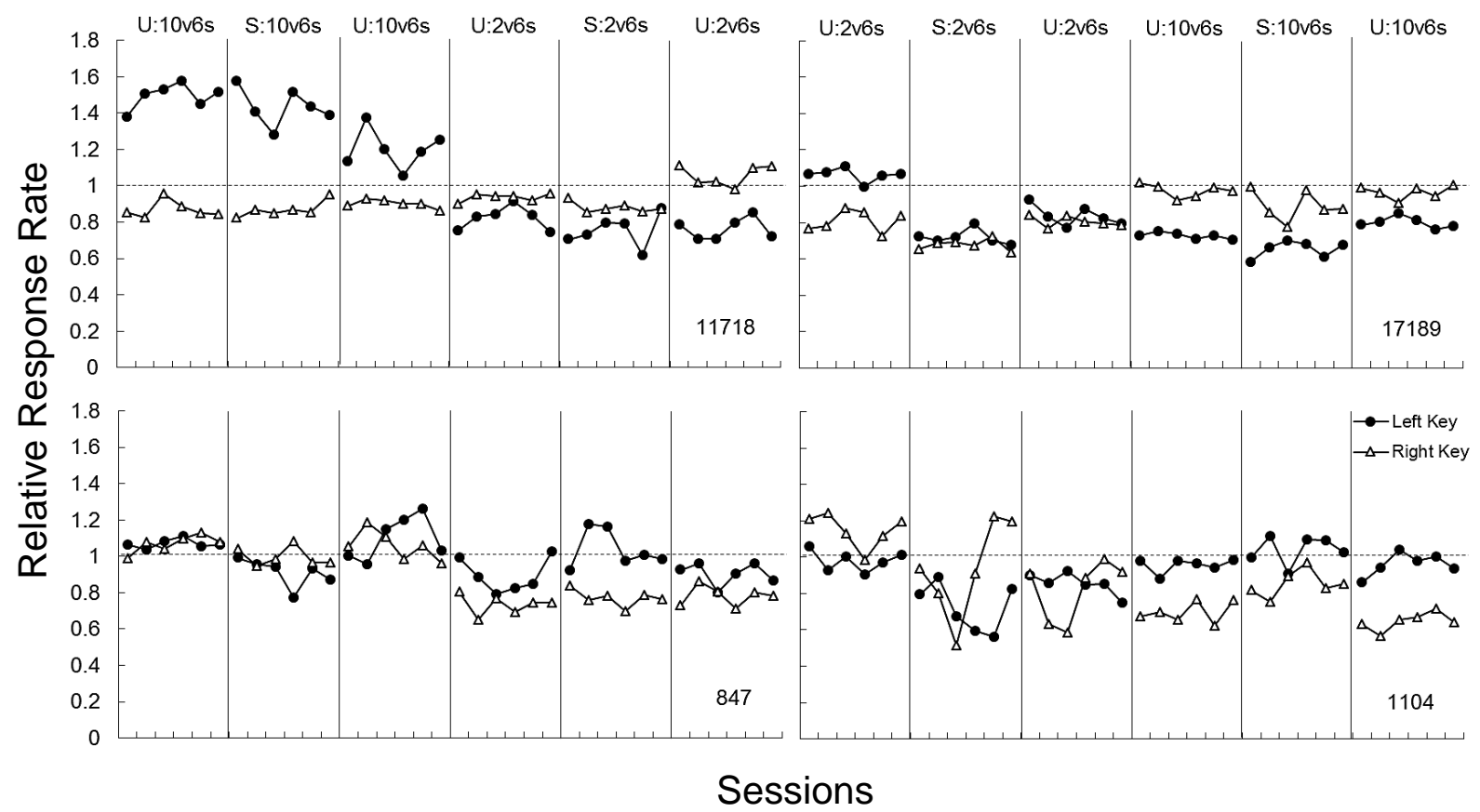

Figure 8. Relative response rates for both the left and right keys during the initial links. Relative response rates on the left key are represented by the black circles and the right key by the open triangles. The dashed line indicates a relative rate of 1 , or no change from baseline response rates. 


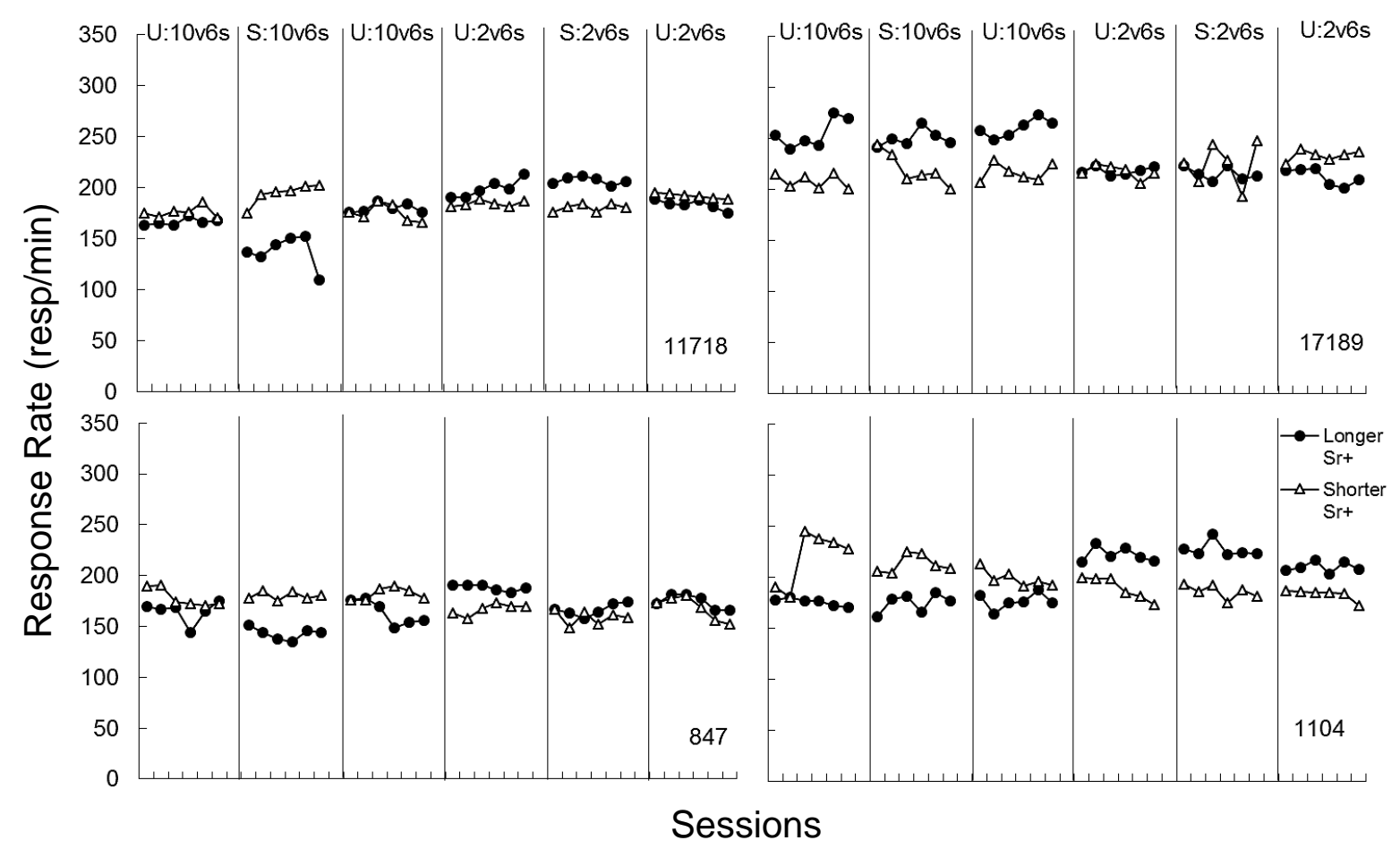

Figure 9. Terminal-link response rates for the last six sessions across all conditions. The terminal link that resulted in the longer-duration reinforcer is represented by the black circles. The terminal link that resulted in the shorter-duration reinforcer is represented by the open triangles. 


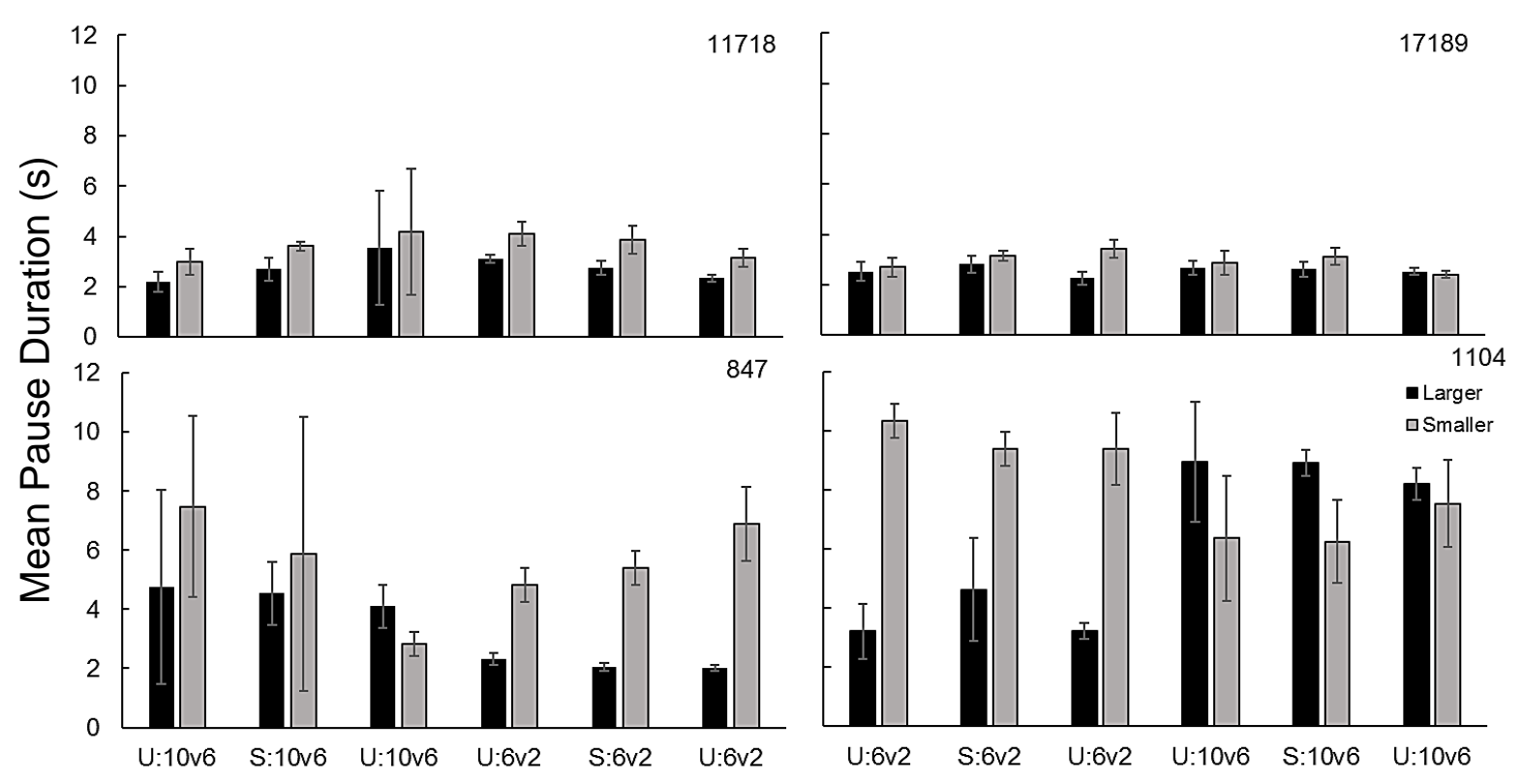

Figure 10. Mean postreinforcement pauses during the last six sessions of each condition. The black bars represent pausing following the delivery of a longer-duration reinforcer and the grey bars represent pausing following shorter-duration reinforcers. The error bars indicate one standard deviation from the mean. 
Appendix A

Raw Data of Initial-Link Response Rates across all Conditions

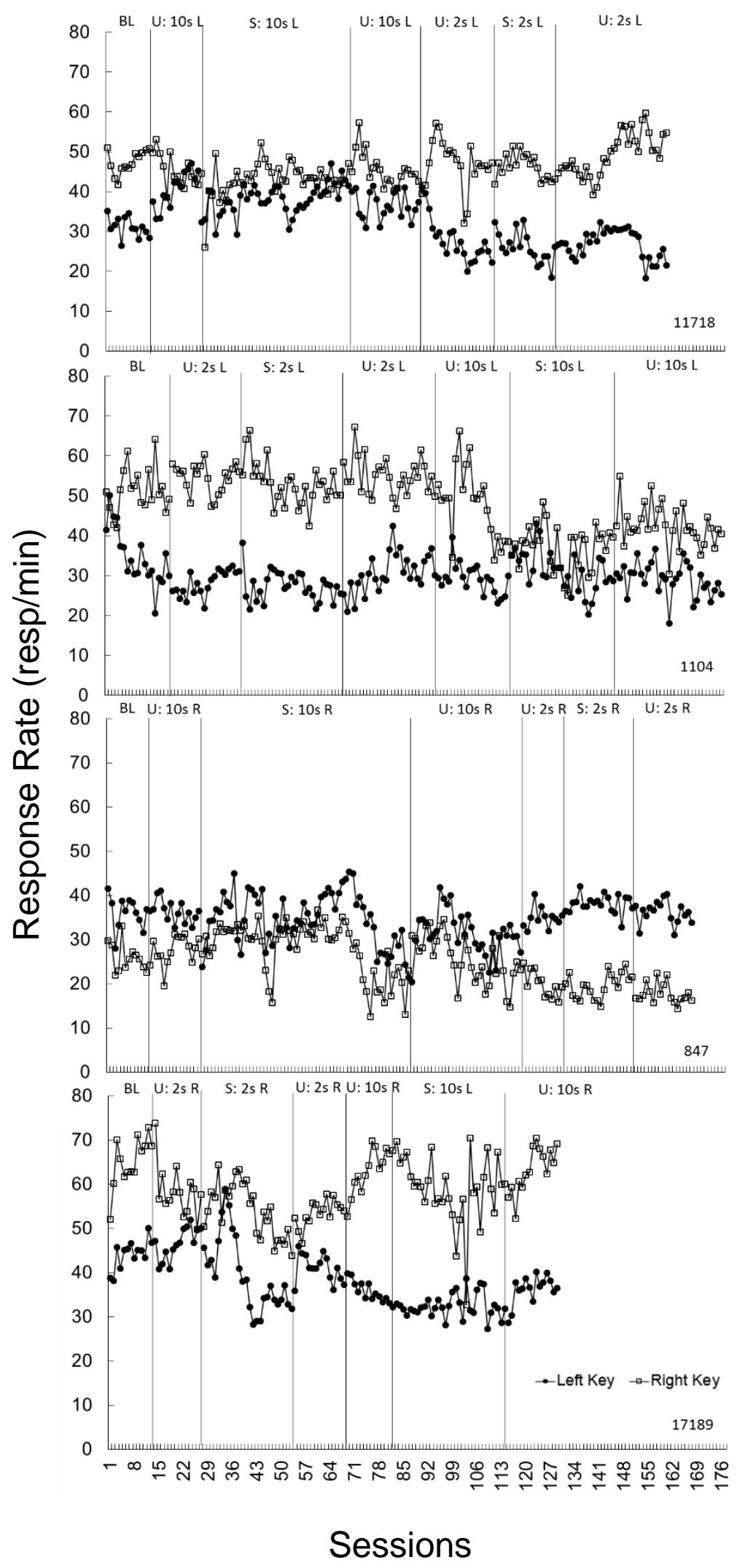

